This is a preprint of the following article: T. F. Wunderlich, S. Dähne, L. Reimer, and A. Schuster. Global AeroStructural Design Optimization of More Flexible Wings for Commercial Aircraft, Journal of Aircraft, September 2021. The original article may differ from this preprint and is available at: https://doi .org/10.2514/1.CQ36301

\title{
Global Aero-Structural Design Optimization of More Flexible Wings for Commercial Aircraft
}

\author{
Tobias F. Wunderlich, Sascha Dähne, Lars Reimer, and Andreas Schuster \\ DLR, German Aerospace Center, 38108 Braunschweig, Germany
}

In the DLR project VicToria (Virtual Aircraft Technology Integration Platform), a process for aerostructural wing optimization based on high fidelity simulation methods is continuously developed. Based upon a parametric geometry, flight performance under transonic flight conditions and maneuver loads are computed by solving the Reynolds-averaged Navier-Stokes equations. Structural mass and elastic characteristics of the wing are determined from structural sizing of the composite wing box for essential maneuver load cases using computational structural mechanics.

Global aero-structural wing optimizations are performed for wings with conventional composite wing box structure and for more flexible wings. The minimization of the fuel consumption for three flight missions represents the objective function. The optimizations are performed for variable and constant wing planform as well as with and without consideration of active maneuver load alleviation. A significant mass reduction of the wing box is obtained with the more flexible wing concept, resulting in a decrease in fuel consumption of about $3 \%$. For the optimizations with active maneuver load alleviation the more flexible wing concept shows an additional reduction of the fuel consumption in the order of $2 \%$. The more flexible wing concept results in optimized wing geometries with increased aspect ratio and reduced taper ratio.

\section{Nomenclature}

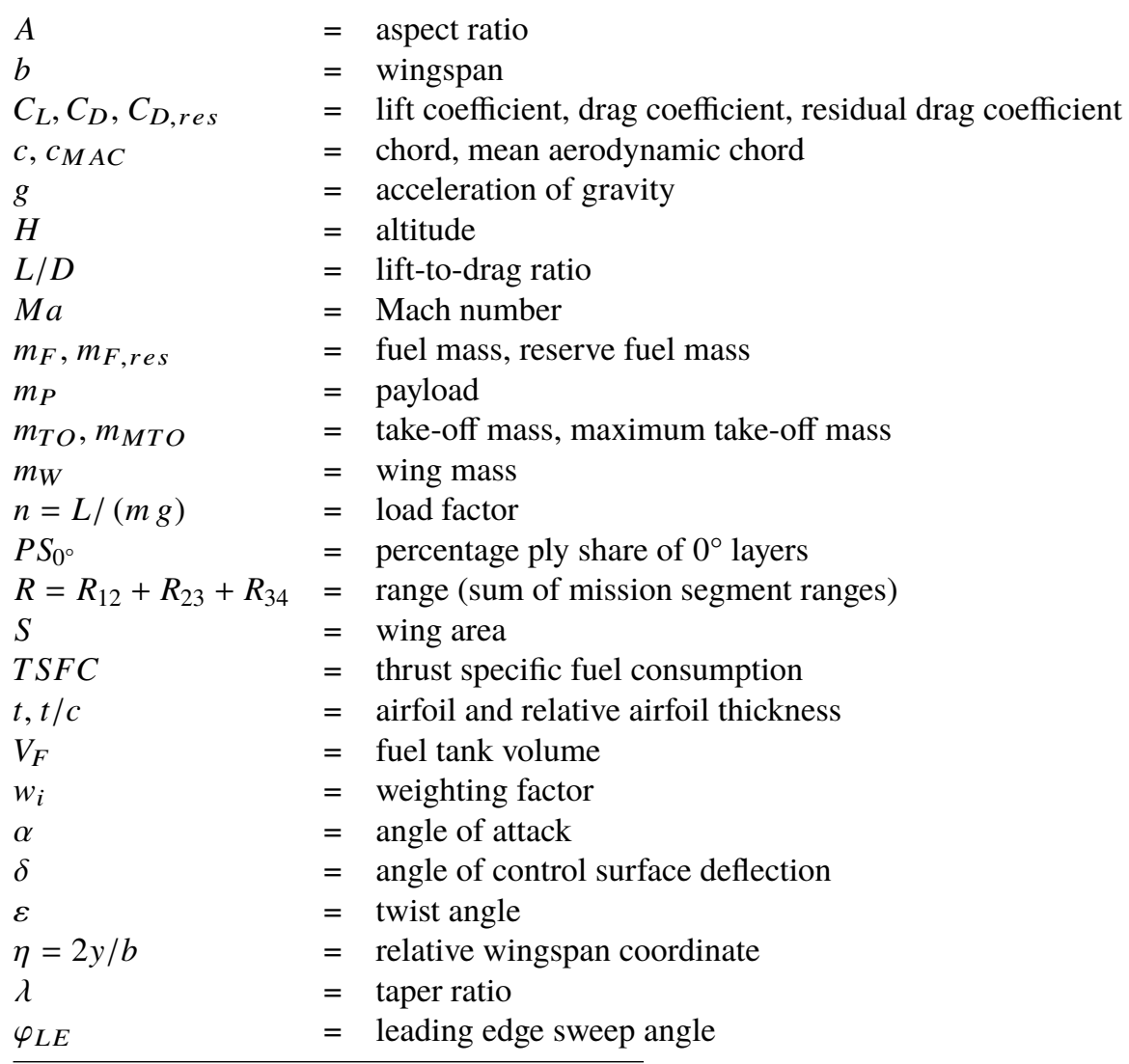

*Presented as Paper 2020-3170 at the AIAA Aviation Forum 2020, Virtual Event, 15-19 June 2020 
Subscripts

cen, in, mid, out

$F S, M S, R S$

$H T P, V T P$

in, out, ail

$M G, N G$

$R i$

$L S$

$W B$
$=$ center, inboard, middle, outboard wing region

$=$ front spar, middle spar, rear spar

$=$ horizontal tailplane, vertical tailplane

= inboard flap, outboard flap, outboard aileron

main gear, nose gear

$=$ ribs

lower skin

= wing fuselage configuration

\section{Introduction}

The environmental impact of commercial aviation increases with the rapid growth of air travel and the $\mathrm{CO}_{2}$ share of aviation will increase due to the increase of renewable energies in other transport sectors and in industry in general. For environmental protection and conservation of resources the main goal of the aeronautical research in Europe and in the United States of America is a strong reduction of the $\mathrm{CO}_{2}$ emissions per passenger kilometer [1-3].

To achieve this challenging goal the development timescales for new technologies have to be reduced significantly. In this context the methodologies and processes for physics based aircraft design and optimization have to be improved. Furthermore, an assessment of new technologies with consideration of all relevant disciplines and their interactions on overall aircraft level will be essential in the future.

The efficiency of commercial aircraft is determined by aerodynamic performance in terms of lift to drag ratio, aircraft empty mass, and thrust specific fuel consumption of the engine. For the accurate drag prediction under cruise flight conditions the flow physics of transonic and turbulent flow can be taken into account by using RANS-based computational fluid dynamics (CFD).

To reduce the structural mass composite materials like carbon fiber reinforced polymers (CFRP) have been introduced in aircraft manufacturing. The corresponding structural concepts and sizing criteria have to be considered in the structural analysis and sizing process by using structural mechanics solvers based on the finite element method (FEM).

Within the aero-structural wing optimization the optimum trade-off between the aerodynamic performance and the wing mass is achieved through combining high fidelity methods for numerical flow simulation of the aircraft outer shape and structural sizing of the wing box with an appropriate optimization algorithm. Thereby, the interaction of aerodynamic forces and wing deformations have to be considered for accurate flight performance and static maneuver loads prediction by using fluid-structure coupling.

Wing design and optimization is a multidisciplinary task with a lot of practical constraints. For example, the size of the tail has to fulfill all stability and control constraints and thus depends on center of gravity range and wing geometry. Furthermore, the landing gear integration and the space allocation for the control surfaces including their actuators have to be considered. Neglecting the landing gear integration leads to unrealistic optimization results as shown in [4].

With increasing knowledge of composite materials further mass reduction potentials can be exploited by better adaptation of fiber direction to internal loads, introduction of advanced structural concepts, and new manufacturing processes. The more flexible wing concept is a result of mass reduction due to new structural concepts with increased strain allowable and applied to the current generation of aircraft from Boeing (Boeing 787 and Boeing 777-8/9). In addition the passive load alleviation due to static aeroelastic effects leads to further wing mass reduction.

The technology of active maneuver load alleviation (MLA) reduces the aerodynamic loads by using trailing edge control surface deflections to adapt the lift distribution under maneuver flight conditions. This technology has been published by White [5] for example and successfully applied to the Lockheed L-1011 [6]. In modern airliners, the maneuver load alleviation functions are an integral part of the flight control system and wing box mass reductions in the order of $0.5 \mathrm{t}$ are feasible for long range aircraft in the Airbus A350 class [7]. The active and passive load alleviation technologies have to be integrated into the sizing process of the aircraft structure and result in longer maintenance intervals and mass reductions. In the context of aircraft conceptual design, $\mathrm{Xu}$ and Kroo [8] have investigated the potential of active load alleviation for fuel burn and direct operating cost reduction. Therefore, a more accurate physical modeling of active maneuver load alleviation technology is pursued in preliminary aircraft design.

Improvements in automation and coupling of accurate simulation methods in combination with advances in numerical optimization strategies lead to the emergence of multidisciplinary design optimization (MDO) based on high fidelity methods. The publications of Sgueglia et al. [9], Papageorgiou et al. [10], Priem et al. [11] and Sarojini et al. [12] are examples for the development and application of modern MDO frameworks. A software solution and its application for distributed multidisciplinary optimization and collaborative process development has been published by Boden et al. [13]. For highly collaborative and computationally intensive multidisciplinary aircraft optimization the cybermatrix protocol has been introduced by Ilic et al. [14]. In addition to the performance indicators based on flight physics the economic aspects have been considered in the context of MDO [15, 16].

The challenge of using MDO based on high fidelity methods is the large number of design parameters and constraints 
and the increased computing effort. To overcome this issue, the adjoint method enables the efficient calculation of the flow variable gradients as a function of the design parameters for gradient based optimization [17, 18]. Up-to-date applications of the adjoint approach for multidisciplinary wing optimization have been shown in the publications of Kenway and Martins [4]; Liem, Kenway, and Martins [19]; Keye et al. [20]; Mader et al. [21]; Brooks and Martins [22]; and Abu-Zurayk et al. [23]. These publications show that the gradient based optimization using the adjoint approach is an adequate method for multidisciplinary wing optimization with high fidelity simulation programs and a large number of design parameters.

In this work an alternative MDO approach is introduced for cases in which gradients cannot be computed efficiently for all relevant disciplines. This applies particularly to cases which involve CAD modeling and structural sizing of composite structures using proprietary codes. Furthermore, a certain degree of flexibility in the process architecture and optimization strategy is desired. Especially the option to use optimization strategies seeking for the global optimum is important. The limitation of this approach is the relatively low number of design parameters in the order of 20 and consequently the airfoil shape optimization is not included in the aero-structural optimization. The focus of the presented approach is to get a better understanding of flight physics, wing design, and current technologies like more flexible wing and active maneuver load alleviation in the preliminary aircraft design stage.

\section{Methods}

In the DLR project VicToria [14, 23-27], an integrated process for aero-structural wing optimization based on high fidelity simulation methods is continuously developed and improved. A detailed description of the original process chain and their successful application has been published by Wunderlich et al. [28, 29]. The improvements described in the current article relate to the introduction of mesh deformation techniques for large geometry changes and simplified control surface deflections. Further extensions include a landing gear integration, a tail sizing based on handbook methods and a trim drag estimation functionality.

The MDO architecture of the integrated process chain falls in the category of MDF optimizations (Multi-Disciplinary Feasible) and can be described as ASO (Asymmetric Subspace Optimization) according to Martins and Lambe [30].

A detailed description of the process chain has been outlined in the corresponding conference publication [31] and only the top level is presented here again.

\subsection{Process chain for aero-structural wing optimization}

The process chain applied is illustrated in terms of XDSM-diagrams (Extended Design Structure Matrix) [32]. Each component in the diagram receives input data in vertical direction and provides output data in horizontal direction. Input and output data are marked by parallelograms. Thick gray lines show the data flow, and thin black arrows indicate the process flow. The numbering system defines the order in which the components are executed.

The flow chart of the process chain for aero-structural wing analysis is shown in Fig. 1. In every optimization step, the geometrical aircraft description of the baseline configuration is recalculated and updated in accordance with the current values of the design parameters. The resulting aircraft geometry is transferred to the subsequent simulation programs by using the Common Parametric Aircraft Configuration Schema (CPACS) [33, 34]. The recalculation of the aircraft geometry includes the wing positioning relative to the fuselage, the integration of the main landing gear, the sizing of the tail, and the check of geometrical constraints.

In the next step the parametric CAD model is updated, the aerodynamic volume mesh is deformed, and the structural model is generated. The parametric CAD model has been built in the commercial software CATIA ${ }^{\circledR}$ V5, which enables accurate surface representation, and robust and time efficient geometry changes.

Within the CFD volume mesh deformation process, the mesh representing the baseline configuration is deformed in two stages for all flight conditions in parallel. In the first stage, the geometrical changes between the baseline and the current geometry are computed based on the corresponding structured multi-block (SMB) surface meshes. The latter result from the automatic surface mesh generation and have an identical mesh topology with the same number of points. For automatic surface mesh generation, the commercial software Pointwise ${ }^{\circledR}$ is applied. In the second stage, the control surface deflections are taken into account. Corresponding to the control surface deflection to be produced, the surface mesh displacement field is computed for each flight condition. It is propagated to the CFD volume mesh by using the Elasticity Analogy (EA) mesh deformation method [35] available in the FlowSimulator [36-38] environment. The used aerodynamic volume mesh consists of $2.16 \cdot 10^{6}$ points for the half model of the wing body configuration. The wing shape has been discretized with 198 points in each airfoil section and with 118 points in span direction. This mesh resolution represents an appropriate trade-off between accuracy and computing effort for wing optimization.

For the generation of the structural model the DLR in-house tool DELiS (Design Environment for thin-walled Lightweight Structures) [39] is used. Based on the central data format CPACS, DELiS automatically generates a consistent finite element mesh by using the open-source tool Gmsh [40]. The finite element model is made up of shells elements enriched with physical properties of the wing spars, ribs, and skin cells and finally exported for the commercial 


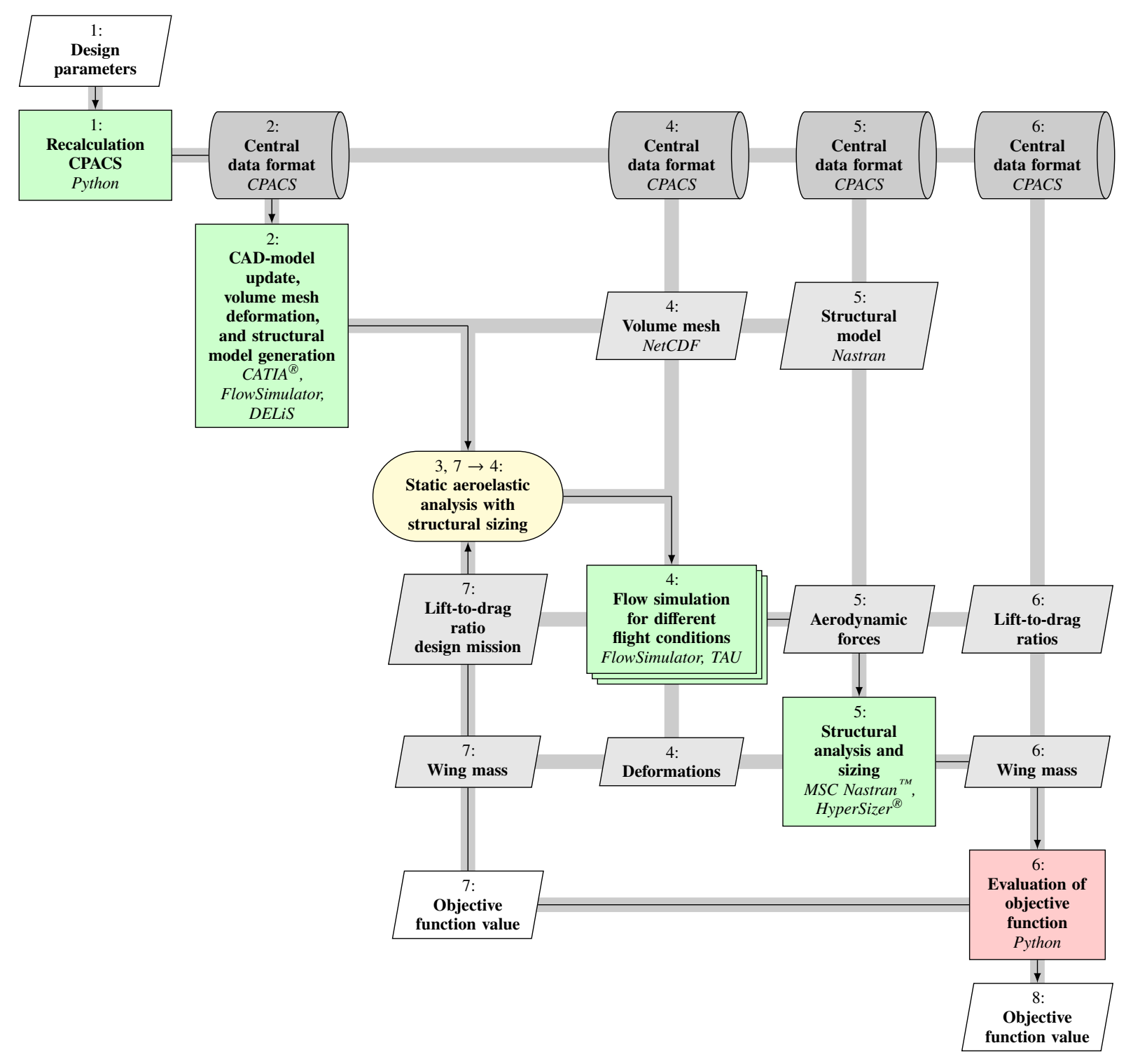

Figure 1: Flow chart of the process chain for aero-structural wing analysis.

FE solver MSC Nastran ${ }^{\mathrm{TM}}$. In this work, the structural model consists of 11700 elements for the half model of the wing box.

The fluid-structure coupling loop is marked with a rounded yellow box and the values of the design mission lift-to-drag ratio, the wing mass and the objective function value are evaluated for the convergence examination. The fluid-structure interaction belongs to the category of loosely coupled analysis [41, 42], with the main difference of replacing the structural analysis of a sized wing structure by a combined structural wing analysis and sizing process. The integration of the structural sizing process into the fluid-structure coupling loop reduces the number of iterations by introducing a damper like behavior.

For all flight conditions the aerodynamic forces and coefficients are computed using RANS-based CFD simulations. The flow simulations are performed by using the DLR TAU-Code $[43,44]$ which is integrated in the HPC framework FlowSimulator [36]. The solver's capabilities with respect to accurate flow predictions, also in near off-design regions, have been demonstrated in numerous publications, including those of the AIAA Drag Prediction Workshop Series [45]. The approach ensures that flight performance under cruise flight conditions and selected maneuver loads with consideration of flow separations are analyzed accurately and efficiently.

Based on the aerodynamic loads computed for the flight conditions considered, the wing-box structure is sized. Within the structural analysis and sizing process the disciplinary objective is to fulfill the structural constraints in terms of failure criteria and converge the margins of safety (MoS) and wing mass. Hence, the structural analysis and sizing process represents a subspace optimization, which is described in detail in the corresponding conference publication [31]. Different design criteria are applied to ensure a valid structural design. As proposed by Dähne et al. [46] for stiffened panels, the criteria for strength, maximum strain, and local and global buckling are used for skin and all stringer 
components. The main results of this process are the wing mass and the deformed wing shapes for the flight conditions considered. The structural analysis and sizing process uses the commercial software MSC Nastran ${ }^{\mathrm{TM}}$ for computing the internal loads and stresses. The commercial software HyperSizer ${ }^{\circledR}$ is applied for sizing the composite wing box.

The structural deformations form the input for the CFD volume mesh deformation. A mesh deformation method based on radial basis functions (RBF) [47] available in the FlowSimulator is used.

Afterwards, the objective function is evaluated and the convergence criteria of the static aeroelastic analysis are examined. The convergence criteria are based on monitoring the changes in lift-to-drag ratio, wing mass, and objective function value. Once convergence of the fluid-structure coupling loop is reached, the objective function value is given to the global optimizer.

After the optimization run has finished the optimized vector of design parameters represents the main result of the process chain for the corresponding optimization problem.

Within this approach, the structural sizing process minimizes the mass of the wing box structure with respect to the panel thicknesses of the structural elements and is representing a subspace optimization. The stiffness of the wing box is a result of this structural sizing process, and the resulting wing deformations have an impact on the cruise flight performance across various flight conditions. This means that the global optimizer has no direct control over the wing stiffness to preserve the optimal wing deformation across different flight conditions. In this context it should be mentioned that the sizing of the wing box structure does not result in the optimum design in terms of the global objective function. Finally, it should be pointed out that this shortcoming will most likely have only a minor impact on the final results.

\subsection{Global optimization strategy}

For the wing optimizations a surrogate based optimization (SBO) method [48] has been selected. This global optimization strategy represents an adequate compromise between exploring the design space and locating the optimum.

The selected optimization method is an implementation of the optimization method EGO (Efficient Global Optimizer), which has been introduced by Jones et al. [49] and has been discussed in Forrester et al. [50].

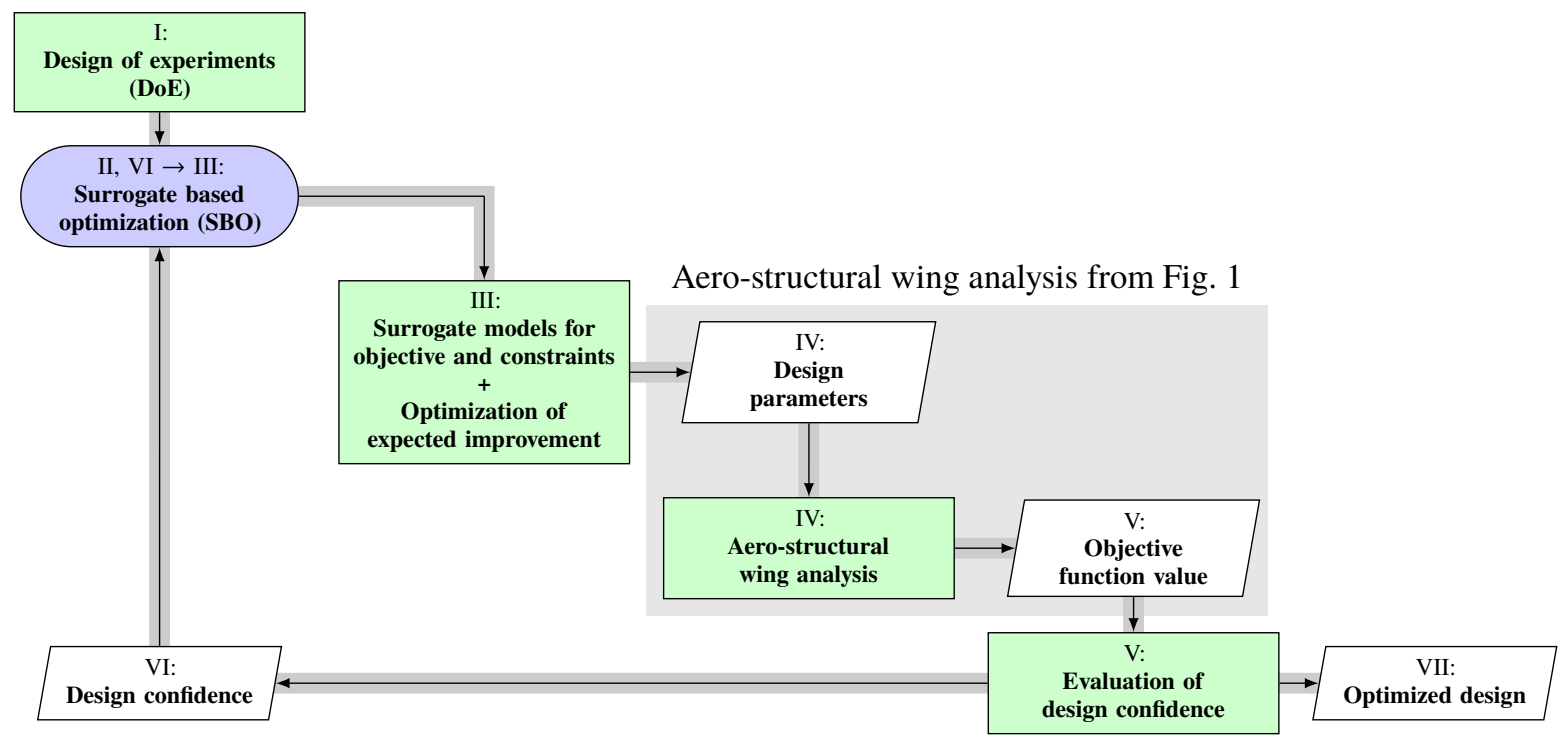

Figure 2: Surrogate based optimization (SBO).

In Fig. 2, a flow chart of the surrogate based optimization with the integrated aero-structural wing analysis process is shown. At the beginning of the optimization a design of experiments (DoE) for a selected number of samples is performed. For the calculated objective function value and for each selected constraint a surrogate model based on kriging [51] is built. These surrogate models are able to model the nonlinear behavior of the objective and constraints. Additionally, a statistical error estimation is included.

Based on the surrogate models of the objective function and constraints, a hybrid optimization strategy is used to find the optimum in terms of expected improvement (EI), which combines the predictions of objective function value and model error. The hybrid optimization strategy starts with a global optimization method and the localization of the optimum is improved by the application of a local optimization method. For the resulting global optimum in terms of expected improvement a recalculation with the physical model is performed. The result of this recalculation is then used to improve the surrogate models for the objective function value and constraints. The described optimization procedure is iterated until convergence is reached. In this work the design confidence [52] is used as convergence criterion. 


\section{Multi-mission aero-structural wing optimizations}

In the DLR project VicToria multi-mission aero-structural wing optimizations have been successfully applied to optimize wing planform, twist, and airfoil thickness distribution of the Airbus XRF1 research configuration. To investigate the more flexible wing concept, the optimizations have been performed for a conventional composite wing structure and for a more flexible composite wing structure. Thereby, the XRF1 is an Airbus provided industrial standard multi-disciplinary research test case representing a typical configuration for a long range wide body aircraft.

In the first step, the wing optimizations with a conventional composite wing structure have been performed. The result of the twist and airfoil thickness distribution optimization represents the baseline. With the optimization of wing planform, twist, and airfoil thickness distribution, the design space has been further extended and shows the full potential of multidisciplinary wing optimization with the introduced optimization approach. Additionally, a result for the optimization of wing planform, twist, and airfoil thickness distribution with consideration of maneuver load alleviation by using active control surface deflections is presented.

In the next step the more flexible wing has been introduced by changing the structural concept and the maximum strain allowable. For the baseline with a more flexible wing, the composite layer distribution of the skins, spars, and ribs and the twist and airfoil thickness distribution have been optimized. The resulting composite layer distribution has been transferred to the other more flexible wing optimizations. In these more flexible wing optimizations the wing planform, twist, and airfoil thickness distribution have been optimized for fixed composite layer distribution with and without the consideration of active maneuver load alleviation, respectively. The composite layer distribution has been fixed to reduce the number of design parameters, to overcome existing computing time limitations of the introduced approach and enable the optimization of the wing planform with additional design parameters for the control surface deflections. With the fixed composite layer distribution the degree of freedom to find the optimal trade between strength and stability criteria in the wing box structure is omitted.

\subsection{Design task}

The design task describes the objective function, the design space, and the constraints. In this work the wing design for a long range commercial aircraft configuration has been selected.

\subsubsection{Objective function, flight missions, and load cases}

The objective function of the multi-mission aero-structural wing optimizations is the combined fuel consumption of three selected flight missions. In this work, the fuel consumption is defined in terms of fuel burn per range and payload. Hence, the combined fuel consumption is the weighted sum of the corresponding mission fuel consumption as given in Eq. (1).

$$
\frac{m_{F}}{R m_{P}}=\sum_{i} w_{i}\left(\frac{m_{F}}{R m_{P}}\right)_{i}
$$

In Table 2 an overview of the selected flight missions and weighting factors is shown. With the selected weighting factors the expected relative frequency of the missions in operation has been considered.

\begin{tabular}{|c|c|c|c|c|c|}
\hline \multirow{6}{*}{ Flight missions } & & & Study mission & High speed mission & Design mission \\
\hline & Weighting factor & $w_{i}$ & 0.6 & 0.1 & 0.3 \\
\hline & Cruise Mach number & $M a$ & 0.83 & 0.85 & 0.83 \\
\hline & Range & $R$ & $4000 \mathrm{~nm}(7408 \mathrm{~km})$ & $4000 \mathrm{~nm}(7408 \mathrm{~km})$ & $6500 \mathrm{~nm}(12038 \mathrm{~km})$ \\
\hline & Payload & $m_{P}$ & $40800 \mathrm{~kg}$ & $40800 \mathrm{~kg}$ & - \\
\hline & Reserve fuel ratio & $m_{F, \text { res }} / m_{F}$ & 0.1410 & 0.1410 & 0.0950 \\
\hline \multirow{5}{*}{ Load cases } & & & Pull up maneuver & Push over maneuver & Roll maneuver \\
\hline & Altitude & $H$ & $0 \mathrm{~m}$ & $6096 \mathrm{~m}$ & $0 \mathrm{~m}$ \\
\hline & Mach number & $M a$ & 0.552 & 0.784 & 0.552 \\
\hline & Lift coefficient wing fuselage & $C_{L, W B}$ & 0.739 & -0.319 & 0.493 \\
\hline & Load factor & $n$ & 2.5 & -1.0 & 1.667 \\
\hline
\end{tabular}

Table 2: Flight missions and load cases.

For the study and design mission the design Mach number of the Airbus XRF1 has been selected. The design mission range is set to $6500 \mathrm{~nm}$ and the corresponding payload is a result of the aero-structural wing analysis. The selection of range and payload for the study mission is based on a typical long range mission with a load factor of 0.85 and represents the mission for which the aircraft will be optimized primarily. The difference between the high speed and the study mission is the increased cruise Mach number to consider off-design conditions in the wing optimization.

For the structural sizing of the wing box the maneuver load cases with the maximum loads have to be defined. These maneuver load cases have been derived from the flight envelope limits and the limits of the maneuvering load factor 
resulting from the certification regulations CS-25/FAR 25. In Tab. 2 an overview of the selected maneuver load cases is given.

To compute the fuel consumption of each flight mission a modeling from conceptual design [53, 54] has been used. Thereby, the flight mission has been divided into five segments and the corresponding aircraft mass fractions have been transferred from typical values given in the textbook published by Jenkinson [55] to the Airbus XRF1 reference aircraft configuration. The flight mission segments are summarized in Table 3.

\begin{tabular}{clcc}
\hline Segment number & Mission segment & Aircraft mass fraction & Reference \\
\hline 1 & Taxi and take-off & $m_{1} / m_{T O}=0.997$ & \\
2 & Climb and accelerate & $m_{2} / m_{1}=0.981$ & {$[55]$} \\
3 & Cruise & $m_{3} / m_{2}=\exp \left(-\frac{\left(C_{1}+C_{2} M a\right) R_{23}}{a_{S L} M a L / D}\right)$ & {$[55]$} \\
4 & Descent for landing & $m_{4} / m_{3}=0.998$ & {$[55]$} \\
5 & Landing and taxi & $m_{5} / m_{4}=0.997$ & {$[55]$} \\
\hline
\end{tabular}

Table 3: Flight mission segments.

For the cruise segment of the flight mission a constant Mach number and constant lift-to-drag ratio have been assumed. Furthermore, the thrust specific fuel consumption has been modeled by a formula published by Mattingly [56]. This formula describes the dependency of the thrust specific fuel consumption from the flight conditions for a given engine and has been adapted to a typical engine map in the Rolls-Royce Trent 1000 class. The formula with the adopted parameters are given in Eq. (2).

$$
T S F C=\frac{C_{1}+C_{2} M a}{g} \sqrt{\frac{\theta}{\theta_{S L}}} \quad \text { with } \quad C_{1}=0.245 \mathrm{~h}^{-1} \quad \text { and } \quad C_{2}=0.415 \mathrm{~h}^{-1}
$$

The aircraft mass fraction for the cruise segment is calculated with Eq. (3), which has been derived from the well-known Breguet range equation and the thrust specific fuel consumption of Eq. (2).

$$
R_{23}=a_{S L} \frac{M a}{C_{1}+C_{2} M a} \frac{L}{D} \ln \frac{m_{2}}{m_{3}} \quad \text { with } \quad a_{S L}=\sqrt{\kappa R \theta_{S L}}=340.3 \mathrm{~m} / \mathrm{s}
$$

For each flight mission the corresponding lift-to-drag ratio for the cruise segment is a result of the aerodynamic coefficients of the flow simulation for the wing body configuration, the estimated aerodynamic coefficients of the tail, and the given residual drag coefficient as shown in Eq. (4).

$$
\frac{L}{D}=\frac{C_{L}}{C_{D}}=\underbrace{\frac{\overbrace{C_{L, W B}}^{\text {flow simulation }}+C_{L, H T P}}{C_{D, W B}}+C_{D, H T P}+C_{D, V T P}+\underbrace{C_{D, \text { res }}}_{\text {const. }}}_{\text {flow simulation }}
$$

The lift coefficient of the horizontal tail is a result of aircraft trimming for the prescribed center of gravity position. This aircraft trimming loop based on the equilibrium of forces and moments around the center of gravity is not described in detail here. For the drag coefficient prediction of the tail a simplified approach from conceptual design [57] based on Prandtl's lifting-line theory and flat plate analogy has been used.

The take-off mass of the aircraft is the sum of the residual mass $m_{\text {Res }}$ (structural mass without the wing and tail including the operating items mass), the wing mass $m_{W}$, the tail mass, the payload, and the fuel masses (mission and reserve fuel) as shown in Eq. (5).

$$
m_{T O}=\overbrace{m_{R e s}+m_{W}+m_{H T P}+m_{V T P}}^{\text {operating empty mass }\left(m_{O E}\right)}+m_{P}+m_{F}+m_{F, \text { res }}
$$

The wing mass is a result of the structural sizing of the wing box and the tail mass is estimated by scaling the tail mass of the reference aircraft with the tail surface ratio after tail sizing. Thereby, the tail sizing is based on conceptual design methods by using constant tail volume coefficients [54]. The fuel mass follows directly from the aircraft mass difference for the complete flight mission.

For the calculation of the fuel consumption the required equations are listed in Table 4 . Thereby, the fuel mass ratio $m_{F} / m_{T O}$ is computed from the aircraft mass fractions with the given range $R$ and the lift-to-drag ratio $L / D$ for the cruise segment. For the study mission and the high speed mission the payload is specified and the take-off mass has to be calculated. In the design mission the take-off mass equals the maximum take-off mass and the payload is resulting from the cruise flight performance and wing mass. For both cases the corresponding equations are evaluated in terms of the payload ratio $m_{P} / m_{T O}$. With the fuel mass ratio and the payload ratio the fuel consumption per range and payload follows directly from the last equation in Table 4. 


\begin{tabular}{ll}
\hline Fuel mass ratio & $\frac{m_{F}}{m_{T O}}=1-\frac{m_{1}}{m_{0}} \frac{m_{2}}{m_{1}} \frac{m_{3}}{m_{2}} \frac{m_{4}}{m_{3}} \frac{m_{5}}{m_{4}}$ \\
Payload ratio & $\frac{m_{P}}{m_{T O}}= \begin{cases}1-\frac{m_{O E}}{m_{T O}}-\left(1+\frac{m_{F}, r e s}{m_{F}}\right) \frac{m_{F}}{m_{T O}} & \text { for specified } m_{T O} \text { and variable } m_{P} \\
\frac{1-\left(1+\frac{m_{F}, r e s}{m_{F}}\right) \frac{m_{F}}{m_{T O}}}{m_{O E}+m_{P}} m_{P} & \text { for specified } m_{P} \text { and variable } m_{T O}\end{cases}$ \\
\hline Fuel consumption & $\frac{m_{F}}{R m_{P}}=\frac{m_{F}}{m_{T O}} \frac{m_{T O}}{m_{P}} \frac{1}{R_{12}+R_{23}+R_{34}}$ \\
\hline
\end{tabular}

Table 4: Used formulas for the computation of the fuel consumption.

\subsubsection{Design parameters and constraints}

The outer shape of the wing has been parameterized with the design parameters shown in Fig. 3. Thereby, the wing planform is calculated from wing area, aspect ratio, leading edge sweep angle, and the taper ratios of the inboard, mid wing, and outboard wing region. Furthermore, the twist and relative airfoil thickness distribution are defined in the corresponding wing sections. In the wing sections between these sections the values of the twist and relative airfoil thickness are interpolated linearly. The fuselage shape has been held constant during the wing optimizations. For the belly fairing an adaptation to the root section of the wing has been considered by scaling the length of the middle section of the belly fairing. The aerodynamic shapes of the front and rear section remain unchanged. The positioning of the wing in $\mathrm{x}$-direction has been performed by maintaining the $\mathrm{x}$-position of the aerodynamic center.
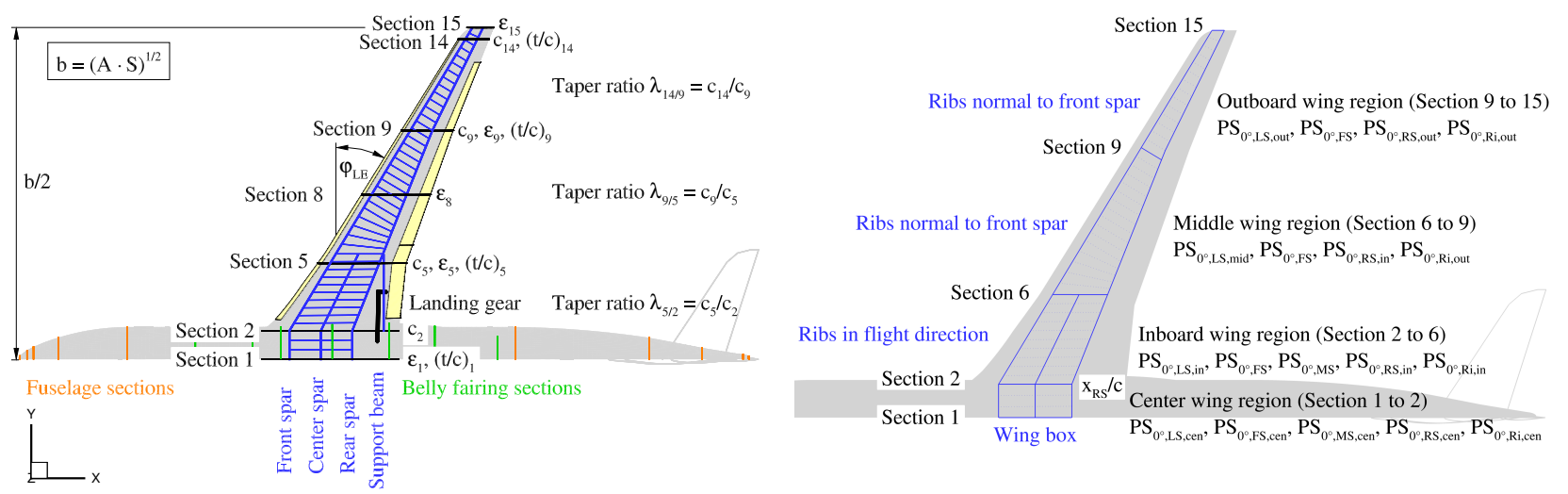

Figure 3: Definition of outer shape design parameters and global wing box design parameters.

The wing box regions and the global wing box design parameters are shown in Fig. 3. Thereby, the wing box has been separated into four regions. The definition of the spars is based on the relative positioning of spar points, which are given in relative span and relative chord coordinates. For the ribs a constant rib spacing has been considered. In the center wing and inboard region the ribs are oriented in flight direction and in the middle and outboard wing region the ribs are positioned normal to the front spar. These rib orientations are typical for Airbus aircraft. For the structural optimization of the wing box the percentage ply share of the lower skin, spars, and ribs have been defined as global design parameters in the four selected wing regions. With this definition the global optimization process gets more control over the structural sizing process with regard to the trade between strength and stability criteria. Furthermore, the percentage ply share of the wing box structure has an impact on the ratio between bending and torsional stiffness of the wing. Consequently, the interactions between wing stiffness, aerodynamic loads, and cruise flight performance are considered in the global optimization within the limitation to wing box structures, which are sized for minimal mass. The wing mass minimization of the structural sizing process is performed for a fixed set of aerodynamic loads and the influence of the local design parameters is limited. In Table 5 all selected global design parameters are summarized with their corresponding lower and upper bound.

The definition of the control surfaces is shown in Fig. 3. For the consideration of the active maneuver load alleviation the deflections of the inboard flap, outboard flap, and outboard aileron have been used as global design parameters in the corresponding wing optimizations.

During the wing optimization the required fuel tank volume is being calculated for all selected flight missions and compared with the useable fuel tank volume. The fuel tank volume constraint has been considered in all wing optimizations.

With the consideration of geometry constraints for the integration of a landing gear and the control surfaces, a better comparability of the optimization results with the baseline aircraft configuration has been achieved. The geometry 
constraints for the landing gear are described in the literature $[54,58,59]$ and the space requirements for control surface actuators are derived from three side views of long range aircraft [60]. Figure 4 gives an overview of the used parameters to define the geometrical constraints, which have to be fulfilled for each wing design. This includes the positioning of the main gear wheel on the ground with a given relative x-position while maintaining the minimal allowed distances between the main landing gear, the control surfaces, and the wing box.
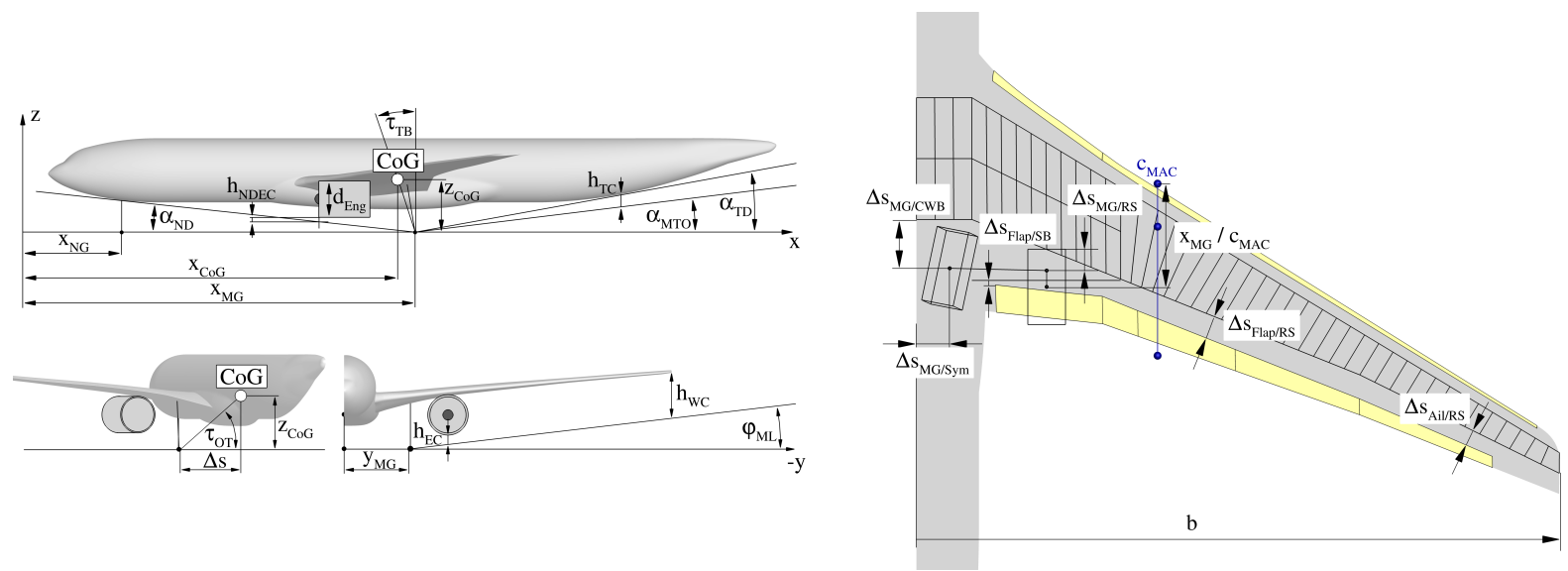

Figure 4: Parameters for the definition of geometrical constraints.

In Fig. 4 further parameters which define the geometrical constraints for the landing gear integration are shown. For each aircraft category the outer main gear wheel span has to be within the given limits. Furthermore, the geometrical constraints for nose down engine clearance $h_{N D E C}$, touch down tail clearance $h_{T C}$, and engine and wing clearances $h_{E C}, h_{W C}$ for a bank angle of $\varphi=5^{\circ}$ have to be fulfilled. The selected values are given in Table 5 .

The introduced landing gear integration consists of a design loop for automatic positioning. Thereby, the main gear wing attachment point is shifted from inboard to outboard position and from front to rear position for each span location. All geometrical constraints are checked for each prescribed position, until a feasible design is found.

In Table 5 the introduced design parameters and constraints are summarized. The design parameters include wing planform and wing section parameters. In addition, the percentage ply share in $10 \%$ steps of the skins, spars, and ribs have been used as design parameters for the more flexible wing optimization. For the conventional composite wing structure of the baseline configuration a fixed standard ply share has been used.

The constraints consist of mass constraints, propulsion constraints, geometrical constraints for airport conformity, landing gear and control surface integration constraints, flight mission constraints, and structural sizing constraints. In Table 5 the used values and there limits are given. 


\begin{tabular}{|c|c|c|c|c|c|}
\hline $\begin{array}{l}\text { Objective } \\
\text { function }\end{array}$ & Combined fuel consumption & $\frac{m_{F}}{R m_{P}}$ & \multicolumn{3}{|c|}{$\min \left\{\sum_{i} w_{i}\left(\frac{m_{F}}{R m_{P}}\right)_{i}\right\}$} \\
\hline \multirow{11}{*}{$\begin{array}{l}\text { Aircraft } \\
\text { properties }\end{array}$} & Description & Variable & \multicolumn{3}{|c|}{ Value } \\
\hline & Maximum take-off mass & $m_{M T O}$ & \multicolumn{3}{|c|}{$245000 \mathrm{~kg}$} \\
\hline & Maximum payload & $m_{P, \max }$ & \multicolumn{3}{|c|}{$48000 \mathrm{~kg}$} \\
\hline & Residual mass ratio & $m_{\text {Res }} / m_{M T O}$ & \multicolumn{3}{|c|}{0.3763} \\
\hline & Specific mass of leading edge high lift device & $m_{L E} / S_{L E}$ & \multicolumn{3}{|c|}{$30 \mathrm{~kg} / \mathrm{m}^{2}$} \\
\hline & Specific mass of trailing edge high lift device & $m_{T E} / S_{T E}$ & \multicolumn{3}{|c|}{$50 \mathrm{~kg} / \mathrm{m}^{2}$} \\
\hline & Horizontal tail volume coefficient & $c_{H T P}$ & \multicolumn{3}{|c|}{0.7222} \\
\hline & Vertical tail volume coefficient & $c_{V T P}$ & \multicolumn{3}{|c|}{0.0648} \\
\hline & Rib spacing & $\Delta s_{R i}$ & \multicolumn{3}{|c|}{$0.75 \mathrm{~m}$} \\
\hline & Thrust specific fuel consumption & $T S F C$ & \multicolumn{3}{|c|}{$\frac{0.245 \mathrm{~h}^{-1}+0.415 \mathrm{~h}^{-1} M a}{g} \sqrt{\frac{\Theta}{\Theta_{S L}}}$} \\
\hline & Relative x-position of main gear wheel on ground & $x_{M G} / c_{M A C}$ & \multicolumn{3}{|c|}{0.6} \\
\hline \multirow{17}{*}{$\begin{array}{l}\text { Design } \\
\text { parameters }\end{array}$} & Description & Variable & Value (Baseline) & Lower bound & Upper bound \\
\hline & Wing area & $S$ & $376.2 \mathrm{~m}^{2}$ & $357 \mathrm{~m}^{2}$ & $414 \mathrm{~m}^{2}$ \\
\hline & Aspect ratio & $A$ & 8.946 & 8.5 & 13.4 \\
\hline & Leading edge sweep angle & $\varphi_{L E}$ & $31.8^{\circ}$ & $30.8^{\circ}$ & $34.8^{\circ}$ \\
\hline & Taper ratio inboard & $\lambda_{5 / 2}$ & 0.6434 & 0.4504 & 0.7077 \\
\hline & Taper ratio mid wing & $\lambda_{9 / 5}$ & 0.5833 & 0.3500 & 0.6416 \\
\hline & Taper ratio outboard & $\lambda_{14 / 9}$ & 0.5951 & 0.3571 & 0.6546 \\
\hline & Twist distribution & $\begin{array}{l}\varepsilon_{1}, \varepsilon_{5}, \varepsilon_{8} \\
\varepsilon_{9}, \varepsilon_{15}\end{array}$ & - & \multicolumn{2}{|c|}{ see Fig. 6 and Fig. 12} \\
\hline & Relative airfoil thickness distribution & $\begin{array}{ll}(t / c)_{1}, & (t / c)_{5} \\
(t / c)_{9}, & (t / c)_{14}\end{array}$ & - & \multicolumn{2}{|c|}{ see Fig. 6 and Fig. 12} \\
\hline & Inboard rear spar position & $x_{R S} / c$ & 0.66 & 0.56 & 0.76 \\
\hline & Percentage ply share of lower skin center & $\left(P S_{0^{\circ}, \text { skin }}\right)_{c e n}$ & $70 \%$ & $10 \%$ & $80 \%$ \\
\hline & Percentage ply share of lower skin inboard & $\left(P S_{0^{\circ}, \text { skin }}\right)_{i n}$ & $60 \%$ & $10 \%$ & $80 \%$ \\
\hline & Percentage ply share of lower skin mid wing & $\left(P S_{0^{\circ}, \text { skin }}\right)_{\text {mid }}$ & $60 \%$ & $10 \%$ & $80 \%$ \\
\hline & Percentage ply share of lower skin outboard & $\left(P S_{0^{\circ}, \text { skin }}\right)_{o u t}$ & $40 \%$ & $10 \%$ & $80 \%$ \\
\hline & Percentage ply share of spars & $\left(P S_{0^{\circ}, \text { spar }}\right)_{i}$ & $50 \%$ & $10 \%$ & $80 \%$ \\
\hline & Percentage ply share of ribs & $\left(P S_{0^{\circ}, r i b}\right)_{j}$ & $40 \%$ & $10 \%$ & $80 \%$ \\
\hline & Control surface deflection angles & $\delta_{i n}, \delta_{o u t}, \delta_{a i l}$ & - & $-20^{\circ}$ & $+20^{\circ}$ \\
\hline \multirow{19}{*}{ Constraints } & Description & Variable & Value (Baseline) & Lower bound & Upper bound \\
\hline & Wingspan (FAA Group V/ICAO Code E) & $b$ & $58.01 \mathrm{~m}$ & $52.0 \mathrm{~m}$ & $65.0 \mathrm{~m}$ \\
\hline & Fuel tank volume & $V_{F}$ & $131.7 \mathrm{~m}^{3}$ & $V_{F, \text { req }}$ & - \\
\hline & Outer main gear wheel span (ICAO Code E) & $2 y_{M G}$ & $11.75 \mathrm{~m}$ & $9.0 \mathrm{~m}$ & $14.0 \mathrm{~m}$ \\
\hline & Nose gear static load ratio & $F_{N G} / m g$ & $6.0 \% \ldots 8.4 \%$ & $5 \%$ & $20 \%$ \\
\hline & Tip back angle & $\tau_{T B}$ & $18.4^{\circ} \ldots 25.5^{\circ}$ & $15^{\circ}$ & - \\
\hline & Overturn angle & $\tau_{O T}$ & $40.9^{\circ} \ldots 41.0^{\circ}$ & - & $63^{\circ}$ \\
\hline & Tail down angle & $\alpha_{T D}$ & $11.2^{\circ}$ & $10^{\circ}$ & - \\
\hline & Clearance of the tail & $h_{T C}$ & $0.4 \mathrm{~m}$ & $0.4 \mathrm{~m}$ & - \\
\hline & Clearance of the engine & $h_{E C}$ & $0.9 \mathrm{~m}$ & - & \\
\hline & Clearance of the wing & $h_{W C}$ & $4.6 \mathrm{~m}$ & $0.4 \mathrm{~m}$ & - \\
\hline & Nose down engine clearance & $h_{N D E C}$ & $0.24 \mathrm{~m}$ & $0.2 \mathrm{~m}$ & - \\
\hline & Castor angle of main gear leg & $\tau_{\text {Cas }}$ & $80.6^{\circ}$ & $80^{\circ}$ & $90^{\circ}$ \\
\hline & Distance between main gear and center wing box & $\Delta s_{M G / C W B}$ & $2.24 \mathrm{~m}$ & $2.0 \mathrm{~m}$ & $2.4 \mathrm{~m}$ \\
\hline & Distance between main gear and symmetry plane & $\Delta s_{M G / S y m}$ & $1.50 \mathrm{~m}$ & $1.4 \mathrm{~m}$ & $1.6 \mathrm{~m}$ \\
\hline & Distance between main gear and rear spar & $\Delta s_{M G / R S}$ & $0.95 \mathrm{~m}$ & $0.6 \mathrm{~m}$ & $1.4 \mathrm{~m}$ \\
\hline & Distance between flap and support beam & $\Delta s_{F l a p / S B}$ & $0.20 \mathrm{~m}$ & $0.2 \mathrm{~m}$ & - \\
\hline & Distance between flap and rear spar & $\Delta s_{\text {Flap } / R S}$ & 0.128 & $0.065 c_{M A C}$ & - \\
\hline & Distance between aileron and rear spar & $\Delta s_{A i l / R S}$ & 0.083 & $0.04 c_{M A C}$ & - \\
\hline
\end{tabular}

Table 5: Objective function, design parameters and constraints.

\subsection{Structural concept of conventional composite wing and more flexible wing}

For the more flexible wing the structural concept and the maximum strain allowable have been changed. The structural concept of the conventional composite wing structure consists of classical upper skin ply share and blade stringers. For the strain allowable a conservative value of $3500 \mu \mathrm{m} / \mathrm{m}$ has been selected as proposed in the Military Handbook [61]. Through a detailed consideration of stringer constraints and stiffness, the evaluation of a more flexible wing becomes possible, while relevant structural constraints are considered. For stiffened composite panels the more flexible wing concept has been investigated by Bach and Hühne [62].

In this work, the more flexible wing has been modeled with a stringer dominant structural concept of the upper cover. This includes a selected upper skin percentage ply share of (10/80/10) and the usage of I-stringers. Based on the modified structural concept a value of $5000 \mu \mathrm{m} / \mathrm{m}$ has been selected for the strain allowable of the more flexible 
wing. The percentage ply share of the lower skin, spars, and ribs has been considered in one of the aero-structural wing optimizations. In Table 6 the differences between the structural concepts of the conventional composite wing and the more flexible wing have been summarized.

\begin{tabular}{|c|c|c|c|}
\hline & & $\begin{array}{l}\text { Structural concept of } \\
\text { conventional composite wing }\end{array}$ & $\begin{array}{l}\text { Structural concept of } \\
\text { more flexible wing }\end{array}$ \\
\hline Structural concept of the upper covers & & Skin dominated design & Stringer dominated design \\
\hline Stringer type & & Blade stringer & I-stringer \\
\hline Strain allowable & & $3500 \mu \mathrm{m} / \mathrm{m}$ & $5000 \mu \mathrm{m} / \mathrm{m}$ \\
\hline \multirow{5}{*}{ Percentage ply share } & Wing region & $0^{\circ} / \pm 45^{\circ} / 90^{\circ}$ & $0^{\circ} / \pm 45^{\circ} / 90^{\circ}$ \\
\hline & Upper skin center & $70 / 20 / 10$ & $10 / 80 / 10$ \\
\hline & Upper skin inboard & $60 / 30 / 10$ & $10 / 80 / 10$ \\
\hline & Upper skin mid wing & $60 / 30 / 10$ & $10 / 80 / 10$ \\
\hline & Upper skin outboard & $40 / 50 / 10$ & $10 / 80 / 10$ \\
\hline
\end{tabular}

Table 6: Structural concept overview.

\subsection{Wing optimization results for conventional composite wing structure with and without MLA}

The selected global design parameters of the wing optimizations with conventional composite wing structure are summarized in Table 7. Based on the Airbus XRF1 reference aircraft geometry, the twist and airfoil thickness distribution have been optimized with the result representing the baseline. In the next step the wing planform including the twist and airfoil thickness distribution have been optimized. The last optimization additionally includes the active maneuver load alleviation by using the inboard flap, outboard flap, and outboard aileron deflections. For all cruise flight cases the control surface deflections are set to zero.

\begin{tabular}{|c|c|c|c|c|}
\hline & & $\begin{array}{c}\text { Twist and } \\
\text { airfoil thickness } \\
\text { optimization } \\
\text { (Baseline) }\end{array}$ & $\begin{array}{c}\text { Planform } \\
\text { twist, and } \\
\text { airfoil thickness } \\
\text { optimization }\end{array}$ & $\begin{array}{l}\text { Planform, twist, and } \\
\text { airfoil thickness } \\
\text { optimization } \\
\text { with MLA }\end{array}$ \\
\hline Wing area & $S$ & - & 1 & 1 \\
\hline Aspect ratio & $A$ & - & 1 & 1 \\
\hline Taper ratios & $\lambda_{5 / 2}, \lambda_{9 / 5}, \lambda_{14 / 9}$ & - & 3 & 3 \\
\hline Leading edge sweep angle & $\varphi_{L E}$ & - & 1 & 1 \\
\hline Twist distribution & $\varepsilon_{1}, \varepsilon_{5}, \varepsilon_{8}, \varepsilon_{9}, \varepsilon_{15}$ & 5 & 5 & 5 \\
\hline Airfoil thickness distribution & $(t / c)_{1},(t / c)_{5},(t / c)_{9},(t / c)_{14}$ & 4 & 4 & 4 \\
\hline Control surface extension & $\Delta\left(c_{F} / c\right)$ & - & 1 & 1 \\
\hline Inboard rear spar position & $x_{R S} / c$ & - & 1 & 1 \\
\hline \multirow{2}{*}{ Control surface deflections } & $\delta_{i n, L C 1}, \delta_{o u t, L C 1}, \delta_{\text {ail }, L C 1}$ & - & - & 3 \\
\hline & $\delta_{i n, L C 2}, \delta_{o u t, L C 2}, \delta_{\text {ail }, L C 2}$ & - & - & 3 \\
\hline Global design parameters & $n_{D P}$ & 9 & 17 & 23 \\
\hline
\end{tabular}

Table 7: Global design parameters of wing optimizations with conventional composite wing structure.

The resulting wing geometries and the corresponding twist and airfoil thickness distributions are shown in Fig. 5 . Thereby, the wing planform, the wing box geometry with the spars and ribs, the landing gear including the support beam, and the control surface geometries are presented. In Fig. 6 the twist distribution for the rigid "jig-shape" and the elastic "flight-shape" are shown for the optimized wings. For the structural interpretation of the results the absolute wing airfoil thickness distribution is given in Fig. 6. In addition, the relative airfoil thickness distribution for the aerodynamic interpretation is presented in Fig. 6.

The result of the twist and airfoil thickness optimization shows a wing with a significant thin inboard wing section. With the aero-structural wing optimization an optimal trade-off between cruise flight performance and wing mass in terms of combined fuel consumption has been achieved. In Table 8 an overview of all relevant values is given. The high value of the used fuel tank volume for the design mission indicates that the fuel volume constraint is fulfilled. The results of the wing planform optimizations show increased wingspan and reduced taper ratio. This leads to increased cruise flight performance without drawbacks due to wing mass changes.

In Fig. 7 and Fig. 8 an overview of the aerodynamic results is given for the optimized wings. For each lift distribution in Fig. 8 the related elliptical lift distribution is shown by a dashed dotted line and the corresponding center of lift is indicated by a white square as a reference. The elliptical lift distribution is optimal for planar wings in terms of lift induced drag. For the cruise flight condition the result of the twist and airfoil thickness optimization shows a nearly 

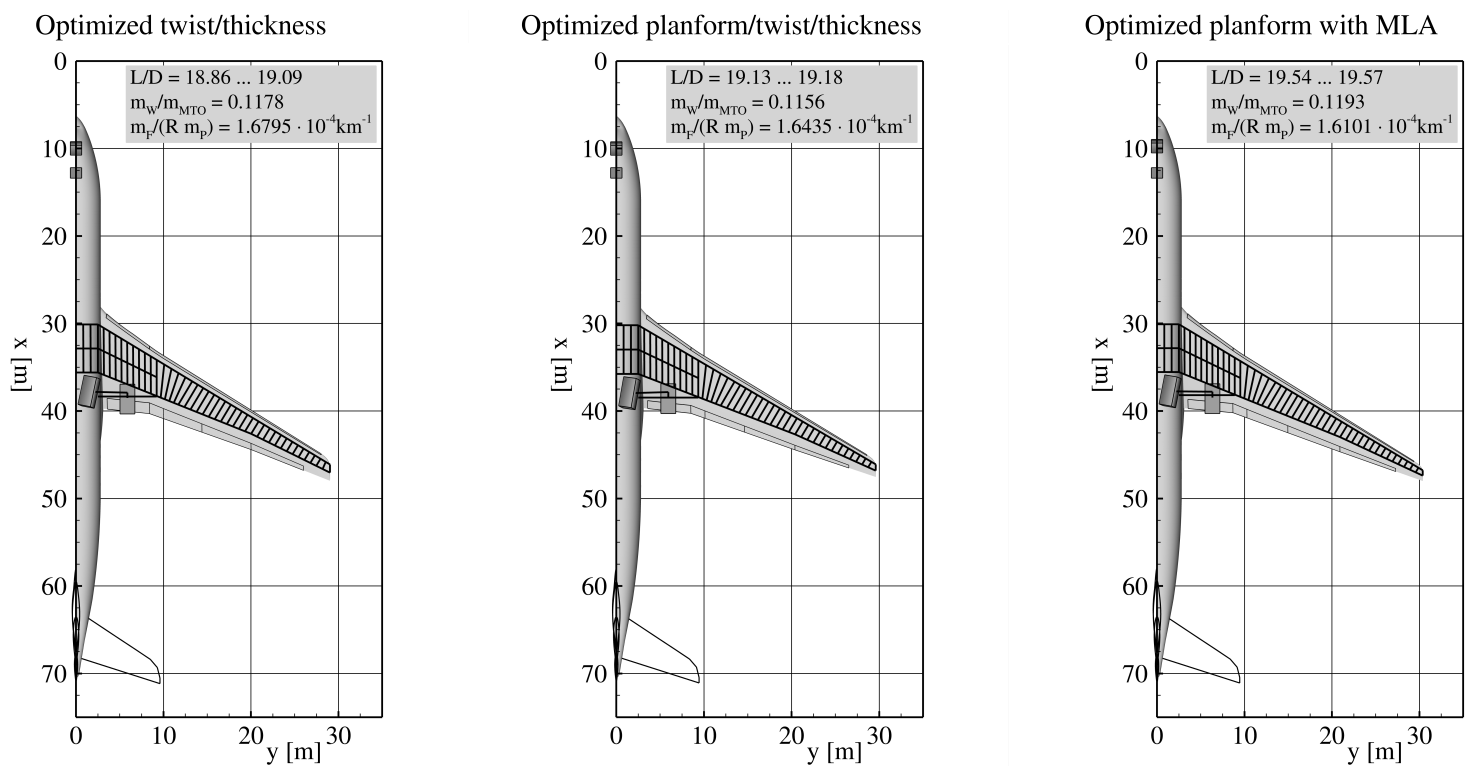

Figure 5: Wing planforms with structure layout of wing optimizations with conventional composite wing structure.
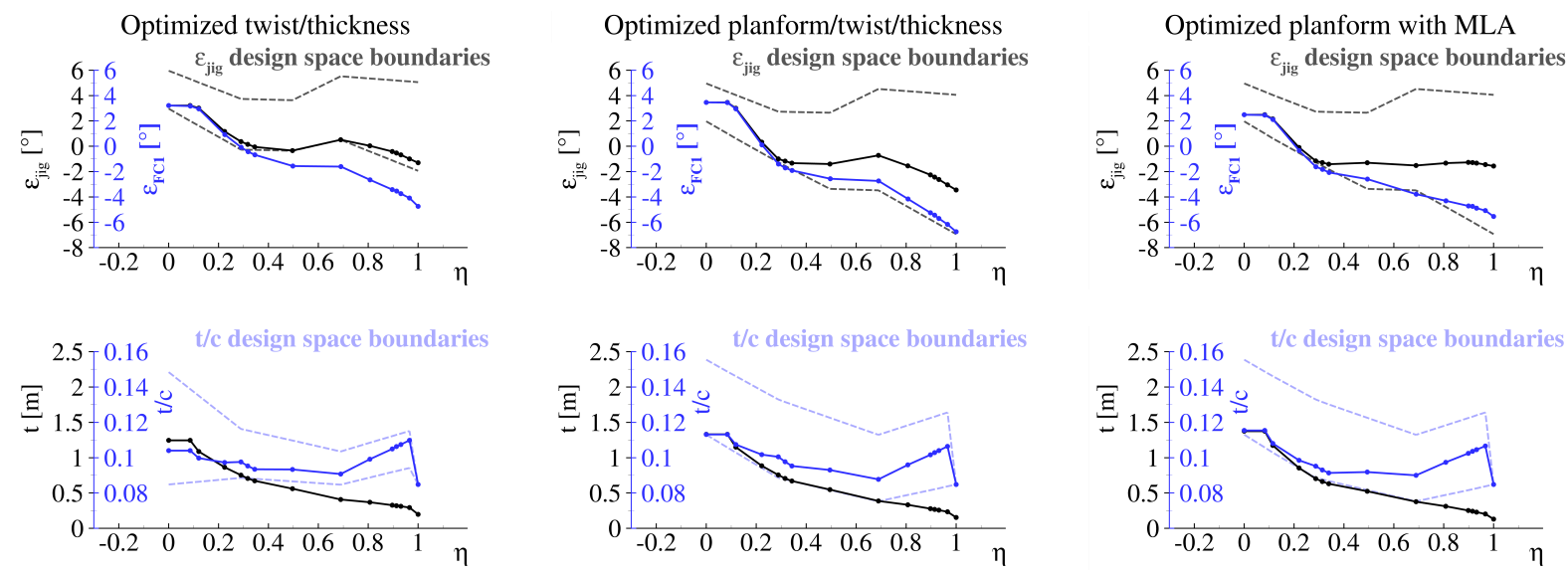

Figure 6: Twist and thickness distributions with the design space boundaries of wing optimizations with conventional composite wing structure.

elliptical lift distribution. The results of the wing planform optimizations show cruise flight lift distributions with increased inboard loading in comparison to the elliptical lift distribution. The corresponding center of lift is indicated by a black circle. In combination with the relative airfoil thickness this leads to higher values for the isentropic Mach number in the inboard wing region. In the pull up maneuver a significant inboard load shift occurs due to static aeroelastic effects of the backward swept wing $[63,64]$. Taking the active maneuver load alleviation into account by deflecting the inboard flap, outboard flap, and outboard aileron the inboard load shift increases.

In addition an overview of the structural results is presented in Fig. 10. The element thicknesses (sum of skin thickness and stringer height) are shown for the spars, ribs, and covers of the sized wing box.

All optimized wings show a similar element thickness distribution. The upper and lower covers have the highest and the biggest panel thicknesses of all components. Therefore, the covers have the biggest mass contribution. All optimization results show a element thickness peak at the engine position and the kink. In the case of active maneuver load alleviation a similar load level is obtained for an increased wingspan. 


\begin{tabular}{|c|c|c|c|c|c|}
\hline & & & $\begin{array}{c}\text { Optimized } \\
\text { twist and } \\
\text { airfoil thickness } \\
\text { (Baseline) }\end{array}$ & $\begin{array}{l}\text { Optimized } \\
\text { planform, } \\
\text { twist, and } \\
\text { airfoil thickness }\end{array}$ & $\begin{array}{c}\text { Optimized } \\
\text { planform, twist, and } \\
\text { airfoil thickness } \\
\text { with MLA }\end{array}$ \\
\hline \multirow{9}{*}{$\begin{array}{c}\text { Wing } \\
\text { Geometry }\end{array}$} & Wing area & $S_{W}$ & $376.2 \mathrm{~m}^{2}$ & $371.1 \mathrm{~m}^{2}$ & $372.0 \mathrm{~m}^{2}$ \\
\hline & Wingspan & $b_{W}$ & $58.01 \mathrm{~m}$ & $59.15 \mathrm{~m}$ & $60.70 \mathrm{~m}$ \\
\hline & Mean aerodynamic chord & $c_{W, M A C}$ & $7.76 \mathrm{~m}$ & $7.61 \mathrm{~m}$ & $7.62 \mathrm{~m}$ \\
\hline & Aspect ratio & $A_{W}$ & 8.946 & 9.428 & 9.904 \\
\hline & Taper ratio & $\lambda_{W}$ & 0.195 & 0.153 & 0.128 \\
\hline & Leading edge sweep angle & $\varphi_{W, L E}$ & $31.9^{\circ}$ & $31.3^{\circ}$ & $31.8^{\circ}$ \\
\hline & Flap spar offset & $\Delta s_{F l a p / R S}$ & $0.99 \mathrm{~m}$ & $1.14 \mathrm{~m}$ & $0.99 \mathrm{~m}$ \\
\hline & Aileron spar offset & $\Delta s_{A i l / R S}$ & $0.64 \mathrm{~m}$ & $0.67 \mathrm{~m}$ & $0.55 \mathrm{~m}$ \\
\hline & Useable fuel tank volume & $V_{F}$ & $108.4 \mathrm{~m}^{3}$ & $112.7 \mathrm{~m}^{3}$ & $110.9 \mathrm{~m}^{3}$ \\
\hline \multirow{2}{*}{$\begin{array}{c}\text { Tail } \\
\text { geometry }\end{array}$} & Horizontal tail area & $S_{H T P}$ & $69.2 \mathrm{~m}^{2}$ & $67.0 \mathrm{~m}^{2}$ & $67.2 \mathrm{~m}^{2}$ \\
\hline & Vertical tail area & $S_{V T P}$ & $49.9 \mathrm{~m}^{2}$ & $50.2 \mathrm{~m}^{2}$ & $51.6 \mathrm{~m}^{2}$ \\
\hline \multirow{7}{*}{$\begin{array}{l}\text { Landing } \\
\text { Gear }\end{array}$} & Outer main gear wheel span & $2 y_{M G}$ & $11.74 \mathrm{~m}$ & $11.86 \mathrm{~m}$ & $12.66 \mathrm{~m}$ \\
\hline & Nose gear static load factor & $F_{N G} /(m g)$ & $0.060 \ldots 0.084$ & $0.059 \ldots 0.083$ & $0.059 \ldots 0.083$ \\
\hline & Tipback angle & $\tau_{T B}$ & $18.6^{\circ} \ldots 25.7^{\circ}$ & $18.3^{\circ} \ldots 25.4^{\circ}$ & $17.4^{\circ} \ldots 24.1^{\circ}$ \\
\hline & Overturn angle & $\tau_{O T}$ & $40.6^{\circ} \ldots 40.7^{\circ}$ & $40.2^{\circ} \ldots 40.3^{\circ}$ & $40.1^{\circ} \ldots 40.3^{\circ}$ \\
\hline & Tail down angle & $\alpha_{T D}$ & $11.0^{\circ}$ & $11.0^{\circ}$ & $11.6^{\circ}$ \\
\hline & Main gear spar offset & $\Delta s_{M G / R S}$ & $0.95 \mathrm{~m}$ & $0.75 \mathrm{~m}$ & $0.70 \mathrm{~m}$ \\
\hline & Main gear flap offset & $\Delta s_{F l a p / S B}$ & $0.20 \mathrm{~m}$ & $0.35 \mathrm{~m}$ & $0.48 \mathrm{~m}$ \\
\hline \multirow{6}{*}{ Masses } & Mass of covers & $m_{W, \text { covers }}$ & $14223 \mathrm{~kg}$ & $13898 \mathrm{~kg}$ & $14879 \mathrm{~kg}$ \\
\hline & Mass of spars & $m_{W, \text { spars }}$ & $2917 \mathrm{~kg}$ & $2954 \mathrm{~kg}$ & $2865 \mathrm{~kg}$ \\
\hline & Mass of ribs & $m_{W, \text { ribs }}$ & $2501 \mathrm{~kg}$ & $2572 \mathrm{~kg}$ & $2513 \mathrm{~kg}$ \\
\hline & Wing box mass & $m_{W, \text { box }}$ & $19640 \mathrm{~kg}$ & $19424 \mathrm{~kg}$ & $20256 \mathrm{~kg}$ \\
\hline & Wing mass ratio & $m_{W} / m_{M T O}$ & 0.1178 & 0.1156 & 0.1193 \\
\hline & Operational empty mass ratio & $m_{O E} / m_{M T O}$ & 0.5199 & 0.5174 & 0.5213 \\
\hline \multirow{2}{*}{$\begin{array}{c}\text { Maneuver } \\
n=2.5\end{array}$} & Lift-to-drag ratio & $L / D$ & 12.40 & 12.89 & 14.26 \\
\hline & Center of pressure & $2 y_{C o P} / b$ & 0.371 & 0.362 & 0.332 \\
\hline \multirow{3}{*}{$\begin{array}{l}\text { Study } \\
\text { mission }\end{array}$} & Lift-to-drag ratio & $L / D$ & 18.86 & 19.13 & 19.54 \\
\hline & Center of pressure & $2 y_{C o P} / b$ & 0.420 & 0.399 & 0.401 \\
\hline & Fuel consumption & $m_{F} /\left(R m_{P}\right)$ & $1.566 \times 10^{-4} \mathrm{~km}^{-1}$ & $1.537 \times 10^{-4} \mathrm{~km}^{-1}$ & $1.513 \times 10^{-4} \mathrm{~km}^{-1}$ \\
\hline \multirow{3}{*}{$\begin{array}{l}\text { High speed } \\
\text { mission }\end{array}$} & Lift-to-drag ratio & $L / D$ & 17.95 & 18.05 & 18.67 \\
\hline & Center of pressure & $2 y_{C o P} / b$ & 0.415 & 0.392 & 0.394 \\
\hline & Fuel consumption & $m_{F} /\left(R m_{P}\right)$ & $1.631 \times 10^{-4} \mathrm{~km}^{-1}$ & $1.616 \times 10^{-4} \mathrm{~km}^{-1}$ & $1.570 \times 10^{-4} \mathrm{~km}^{-1}$ \\
\hline \multirow{5}{*}{$\begin{array}{l}\text { Design } \\
\text { mission }\end{array}$} & Payload & $m_{P}$ & $33278 \mathrm{~kg}$ & $34185 \mathrm{~kg}$ & $34519 \mathrm{~kg}$ \\
\hline & Used fuel tank volume ratio & $V_{F, \text { req }} / V_{F}$ & 0.973 & 0.932 & 0.933 \\
\hline & Lift-to-drag ratio & $L / D$ & 19.09 & 19.18 & 19.57 \\
\hline & Center of pressure & $2 y_{C o P} / b$ & 0.413 & 0.392 & 0.393 \\
\hline & Fuel consumption & $m_{F} /\left(R m_{P}\right)$ & $1.923 \times 10^{-4} \mathrm{~km}^{-1}$ & $1.865 \times 10^{-4} \mathrm{~km}^{-1}$ & $1.819 \times 10^{-4} \mathrm{~km}^{-1}$ \\
\hline Objective & Combined fuel consumption & $m_{F} /\left(R m_{P}\right)$ & $1.680 \times 10^{-4} \mathrm{~km}^{-1}$ & $1.644 \times 10^{-4} \mathrm{~km}^{-1}$ & $1.610 \times 10^{-4} \mathrm{~km}^{-1}$ \\
\hline
\end{tabular}

Table 8: Results overview of wing optimizations with conventional composite wing structure. 

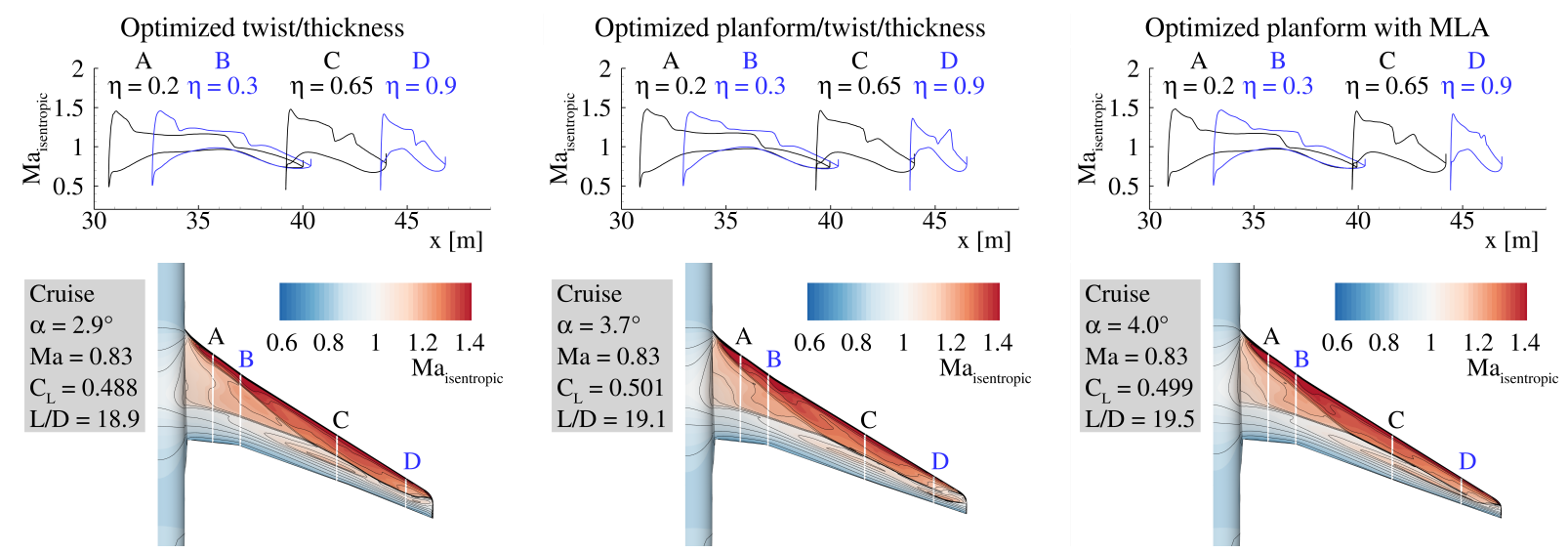

Figure 7: Isentropic Mach number distributions of wing optimizations with conventional composite wing structure.

Optimized twist/thickness

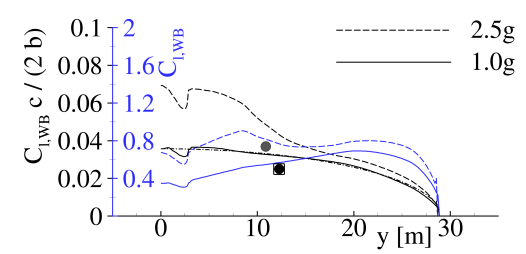

Optimized planform/twist/thickness

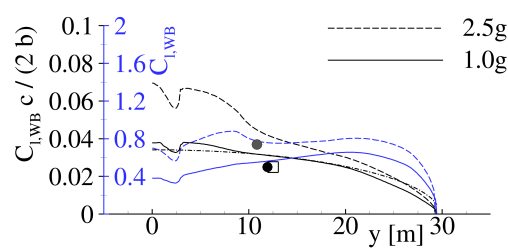

Optimized planform with MLA

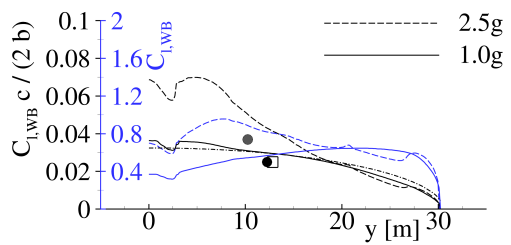

Figure 8: Lift and lift coefficient distributions for cruise and maneuver flight conditions of wing optimizations with conventional composite wing structure.

Optimized twist/thickness

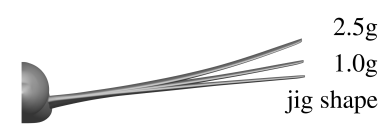

Optimized planform/twist/thickness

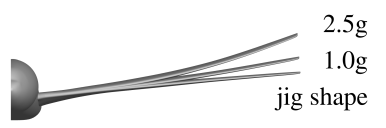

Optimized planform with MLA

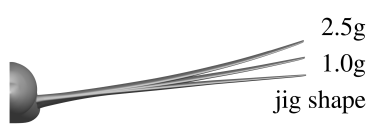

Figure 9: Wing deformations for cruise and maneuver flight conditions of wing optimizations with conventional composite wing structure.

Optimized twist/thickness

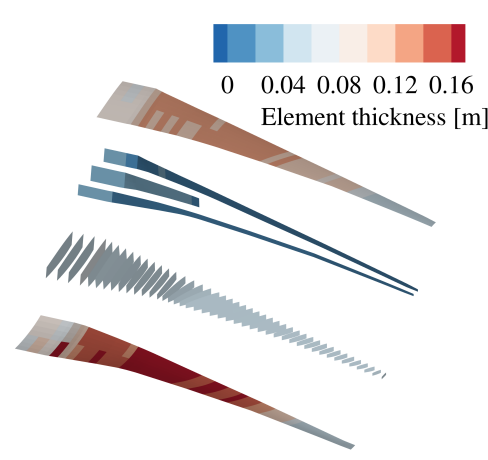

Optimized planform/twist/thickness

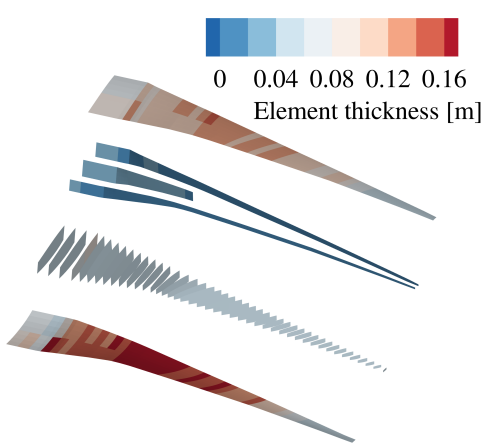

Optimized planform with MLA

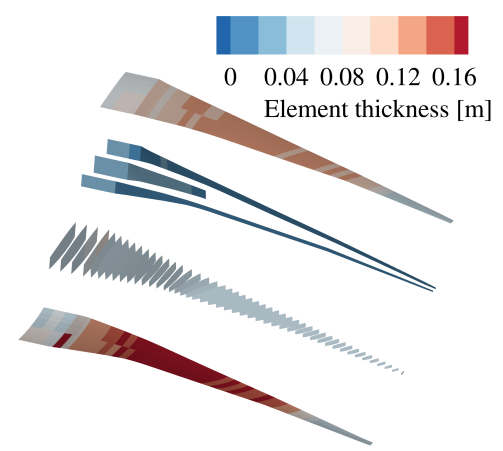

Figure 10: Wing box element thickness (skin thickness + stringer height) distributions of wing optimizations with conventional composite wing structure. 


\subsection{Wing optimization results for more flexible composite wing structure with and without MLA}

The selected global design parameters of the wing optimizations with the more flexible composite wing structure are summarized in Table 9. Based on the Airbus XRF1 reference aircraft geometry the twist and airfoil thickness distribution and the percentage ply share of the lower skin, spars, and ribs have been optimized and the result represents the baseline with the more flexible wing. In the next optimization the wing planform including the twist and airfoil thickness distribution have been optimized. The last optimization additionally includes the active maneuver load alleviation by using the inboard flap, outboard flap, and outboard aileron deflections.

\begin{tabular}{|c|c|c|c|c|}
\hline & & $\begin{array}{c}\text { Baseline } \\
\text { optimization with } \\
\text { more flexible wing }\end{array}$ & $\begin{array}{c}\text { More flexible wing } \\
\text { optimization }\end{array}$ & $\begin{array}{c}\text { More flexible wing } \\
\text { optimization } \\
\text { with MLA }\end{array}$ \\
\hline Wing area & $S$ & - & 1 & 1 \\
\hline Aspect ratio & $A$ & - & 1 & 1 \\
\hline Taper ratios & $\lambda_{5 / 2}, \lambda_{9 / 5}, \lambda_{14 / 9}$ & - & 3 & 3 \\
\hline Leading edge sweep angle & $\varphi_{L E}$ & - & 1 & 1 \\
\hline Twist distribution & $\varepsilon_{1}, \varepsilon_{5}, \varepsilon_{8}, \varepsilon_{9}, \varepsilon_{15}$ & 5 & 5 & 5 \\
\hline Airfoil thickness distribution & $(t / c)_{1},(t / c)_{5},(t / c)_{9},(t / c)_{14}$ & 2 & 4 & 4 \\
\hline Control surface extension & $\Delta\left(c_{F} / c\right)$ & - & 1 & 1 \\
\hline Inboard rear spar position & $x_{R S} / c$ & - & 1 & 1 \\
\hline Percentage ply share lower skin & $P S_{0^{\circ}, \text { LS }, \text { cen } / \text { in } / \text { mid/out }}$ & 4 & - & - \\
\hline Percentage ply share spars & $P S_{0^{\circ}, S p, c e n / \text { in } / o u t}$ & 3 & - & - \\
\hline Percentage ply share ribs & $P S_{0^{\circ}, \text { Ri,cen/in/out }}$ & 3 & - & - \\
\hline \multirow{2}{*}{ Control surface deflections } & $\delta_{i n, L C 1}, \delta_{o u t, L C 1}, \delta_{a i l, L C 1}$ & - & - & 3 \\
\hline & $\delta_{\text {in }, L C 2}, \delta_{\text {out }, L C 2}, \delta_{\text {ail }, L C 2}$ & - & - & 3 \\
\hline Global design parameters & $n_{D P}$ & 17 & 17 & 23 \\
\hline
\end{tabular}

Table 9: Global design parameters for wing optimizations with more flexible wing structure.

The resulting wing geometries are presented in Fig. 11 and the corresponding twist and airfoil thickness distributions are shown in Fig. 12 for the more flexible wing structure. The outer shape and inner wing structure of the more flexible wings are presented in the same way as the wings with conventional wing structure.

The results show very thin inboard wing sections for all optimized more flexible wings. The optima in terms of combined fuel consumption move to cruise flight performance improvements based on further reductions of the relative airfoil thicknesses. The reason for this is the significant mass reduction potential of the more flexible wing. In Table 10 an overview of all relevant values is given. The wing mass of the baseline with more flexible wing has been reduced in the order of $2.5 \mathrm{t}$ in comparison to the twist and airfoil thickness optimized wing with conventional wing structure. The results of the wing planform optimizations show increased wingspan and reduced taper ratio as well. This leads to increased cruise flight performance without drawbacks due to wing mass changes. In comparison to the wings with conventional wing structure the optimization results of the more flexible wing show wing geometries with increased wing area, wingspan, and aspect ratio and similar cruise flight performance in terms of lift-to-drag ratios. The corresponding fuel consumptions have been reduced due to lower operational empty masses. Furthermore, the reduced wing stiffness of the more flexible wings results in more inboard center of pressure positions. The used fuel tank volume ratio of the baseline with the more flexible wing is on the upper limit for the design mission due to the very thin inboard wing. All optimized wings with the more flexible wing structure fulfill the fuel volume constraint.

An overview of the aerodynamic results is given in Fig. 13 and Fig. 14 for the optimized wings with more flexible wing structure in comparison to the optimization results of the wings with conventional wing structure. The resulting wing deformations are presented in Fig. 15 for the cruise flight condition and the $2.5 \mathrm{~g}$ symmetric pull up maneuver in comparison to the rigid jig-shape. The more flexible wings show higher deflections due to the modified structural concept and the increased strain allowable. The results of the wing planform optimizations show cruise flight lift distributions with increased inboard loading in comparison to the elliptical lift distribution as shown in Fig. 14. In the pull up maneuver a significant inboard load shift occurs due to static aeroelastic effects of the backward swept wing. This inboard load shift of the more flexible wings is stronger in comparison to the optimized wings with conventional wing structure. As expected, the inboard load shift increases further with the usage of the active maneuver load alleviation system. The wing planform optimization of the more flexible wing with active maneuver load alleviation shows a strong reduction of wing bending in the pull up maneuver. Thereby, the inboard load shift is related to a forward shifting of the center of pressure in the case of backward swept wings and the aircraft trimming redistributes the lift between the wing and the horizontal tail. As a result, the lift of the horizontal tail increases and simultaneously the lift of the wing decreases.

In analogy to the results for the conventional wing structure an overview of the structural results for the more flexible wing is presented in Fig. 16. With the increased maximum strain allowable the mass of the upper and lower covers 
Baseline with more flexible wing

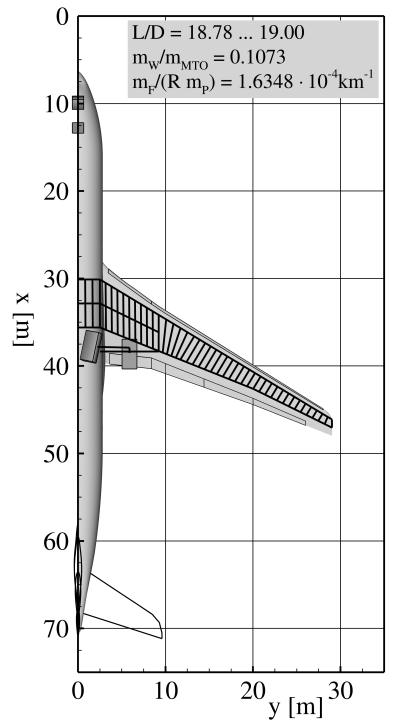

Optimized more flexible wing

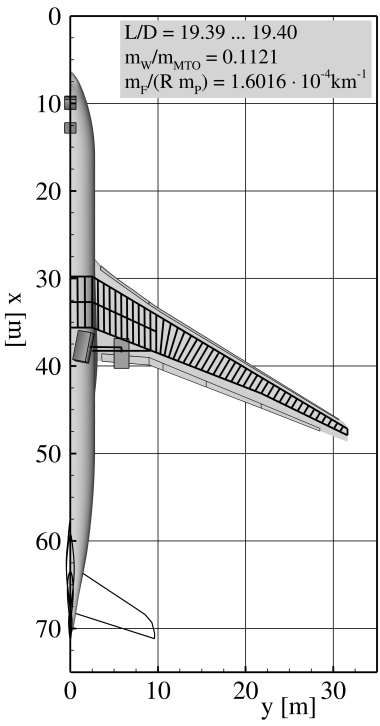

Optimized more flexible wing with MLA

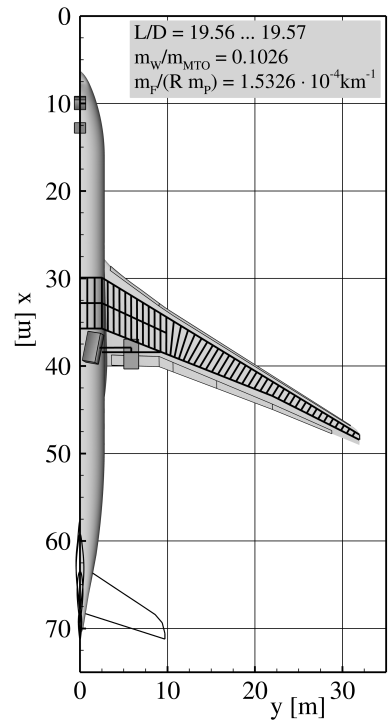

Figure 11: Wing planforms with structure layout of wing optimizations with more flexible wing structure.
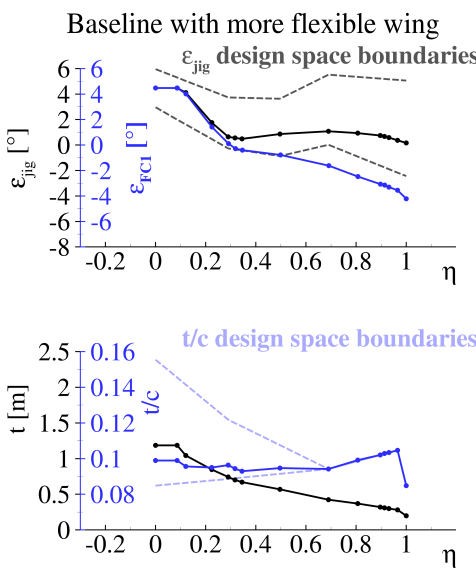
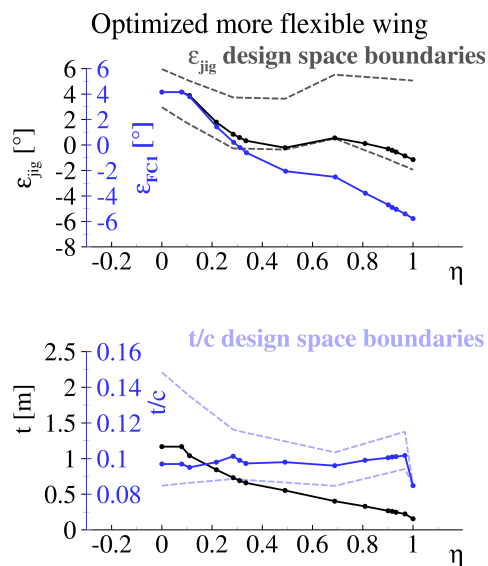

Optimized more flexible wing with MLA
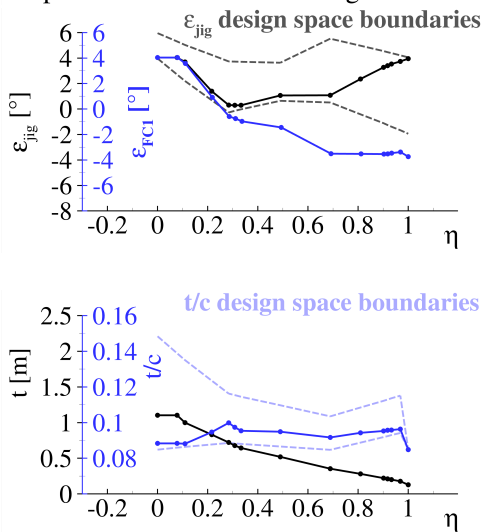

Figure 12: Twist and thickness distributions with the design space boundaries of wing optimizations with more flexible wing structure.

decreases significantly, because the maximum strain criteria is the dominant criteria for the covers on the conventional wing structure. Furthermore, the spars are getting thinner due to the reduced airfoil thickness and the corresponding reduction of buckling areas, where stability is still the sizing criteria for the spars. While optimizing the airfoil thickness the panel thicknesses of the covers increase slightly with decreasing airfoil thicknesses. By introducing the active maneuver load alleviation, the reduced loads level leads to reduced element thicknesses again. 


\begin{tabular}{|c|c|c|c|c|c|}
\hline & & & $\begin{array}{c}\text { Baseline with } \\
\text { more flexible wing }\end{array}$ & $\begin{array}{c}\text { Optimized } \\
\text { more flexible wing }\end{array}$ & $\begin{array}{l}\text { Optimized } \\
\text { more flexible wing } \\
\text { with MLA }\end{array}$ \\
\hline \multirow{9}{*}{$\begin{array}{c}\text { Wing } \\
\text { Geometry }\end{array}$} & Wing area & $S_{W}$ & $376.2 \mathrm{~m}^{2}$ & $387.4 \mathrm{~m}^{2}$ & $384.5 \mathrm{~m}^{2}$ \\
\hline & Wingspan & $b_{W}$ & $58.01 \mathrm{~m}$ & $63.20 \mathrm{~m}$ & $63.79 \mathrm{~m}$ \\
\hline & Mean aerodynamic chord & $c_{W, M A C}$ & $7.76 \mathrm{~m}$ & $7.56 \mathrm{~m}$ & $7.76 \mathrm{~m}$ \\
\hline & Aspect ratio & $A_{W}$ & 8.946 & 10.309 & 10.582 \\
\hline & Taper ratio & $\lambda_{W}$ & 0.195 & 0.154 & 0.120 \\
\hline & Leading edge sweep angle & $\varphi_{W, L E}$ & $31.9^{\circ}$ & $31.6^{\circ}$ & $32.3^{\circ}$ \\
\hline & Flap spar offset & $\Delta s_{\text {Flap } / R S}$ & $0.99 \mathrm{~m}$ & $0.84 \mathrm{~m}$ & $0.59 \mathrm{~m}$ \\
\hline & Aileron spar offset & $\Delta s_{A i l / R S}$ & $0.64 \mathrm{~m}$ & $0.64 \mathrm{~m}$ & $0.45 \mathrm{~m}$ \\
\hline & Useable fuel tank volume & $V_{F}$ & $106.1 \mathrm{~m}^{3}$ & $113.3 \mathrm{~m}^{3}$ & $106.8 \mathrm{~m}^{3}$ \\
\hline \multirow{2}{*}{$\begin{array}{c}\text { Tail } \\
\text { geometry }\end{array}$} & Horizontal tail area & $S_{H T P}$ & $69.2 \mathrm{~m}^{2}$ & $69.4 \mathrm{~m}^{2}$ & $70.7 \mathrm{~m}^{2}$ \\
\hline & Vertical tail area & $S_{V T P}$ & $49.9 \mathrm{~m}^{2}$ & $56.0 \mathrm{~m}^{2}$ & $56.0 \mathrm{~m}^{2}$ \\
\hline \multirow{7}{*}{$\begin{array}{l}\text { Landing } \\
\text { Gear }\end{array}$} & Outer main gear wheel span & $2 y_{M G}$ & $11.76 \mathrm{~m}$ & $11.67 \mathrm{~m}$ & $11.70 \mathrm{~m}$ \\
\hline & Nose gear static load factor & $F_{N G} /(m g)$ & $0.060 \ldots 0.084$ & $0.059 \ldots 0.082$ & $0.060 \ldots 0.084$ \\
\hline & Tipback angle & $\tau_{T B}$ & $18.3^{\circ} \ldots 25.4^{\circ}$ & $17.9^{\circ} \ldots 24.8^{\circ}$ & $18.5^{\circ} \ldots 25.5^{\circ}$ \\
\hline & Overturn angle & $\tau_{O T}$ & $41.0^{\circ} \ldots 41.1^{\circ}$ & $41.1^{\circ} \ldots 41.2^{\circ}$ & $40.9^{\circ} \ldots 41.1^{\circ}$ \\
\hline & Tail down angle & $\alpha_{T D}$ & $11.2^{\circ}$ & $11.2^{\circ}$ & $11.1^{\circ}$ \\
\hline & Main gear spar offset & $\Delta s_{M G / R S}$ & $0.95 \mathrm{~m}$ & $0.95 \mathrm{~m}$ & $0.85 \mathrm{~m}$ \\
\hline & Main gear flap offset & $\Delta s_{\text {Flap } / S B}$ & $0.21 \mathrm{~m}$ & $0.32 \mathrm{~m}$ & $0.31 \mathrm{~m}$ \\
\hline \multirow{6}{*}{ Masses } & Mass of covers & $m_{W, \text { covers }}$ & $11950 \mathrm{~kg}$ & $13267 \mathrm{~kg}$ & $10995 \mathrm{~kg}$ \\
\hline & Mass of spars & $m_{W, \text { spars }}$ & $2428 \mathrm{~kg}$ & $2355 \mathrm{~kg}$ & $2232 \mathrm{~kg}$ \\
\hline & Mass of ribs & $m_{W, \text { ribs }}$ & $2694 \mathrm{~kg}$ & $2915 \mathrm{~kg}$ & $3021 \mathrm{~kg}$ \\
\hline & Wing box mass & $m_{W, \text { box }}$ & $17072 \mathrm{~kg}$ & $18537 \mathrm{~kg}$ & $16247 \mathrm{~kg}$ \\
\hline & Wing mass ratio & $m_{W} / m_{M T O}$ & 0.1073 & 0.1121 & 0.1026 \\
\hline & Operational empty mass ratio & $m_{O E} / m_{M T O}$ & 0.5093 & 0.5149 & 0.5056 \\
\hline \multirow{2}{*}{$\begin{array}{c}\text { Maneuver } \\
\mathrm{n}=\mathbf{2 . 5}\end{array}$} & Lift-to-drag ratio & $L / D$ & 11.51 & 12.73 & 12.87 \\
\hline & Center of pressure & $2 y_{C o P} / b$ & 0.365 & 0.353 & 0.292 \\
\hline \multirow{3}{*}{$\begin{array}{c}\text { Study } \\
\text { mission }\end{array}$} & Lift-to-drag ratio & $L / D$ & 18.78 & 19.40 & 19.57 \\
\hline & Center of pressure & $2 y_{C o P} / b$ & 0.417 & 0.387 & 0.391 \\
\hline & Fuel consumption & $m_{F} /\left(R m_{P}\right)$ & $1.549 \times 10^{-4} \mathrm{~km}^{-1}$ & $1.510 \times 10^{-4} \mathrm{~km}^{-1}$ & $1.476 \times 10^{-4} \mathrm{~km}^{-1}$ \\
\hline \multirow{3}{*}{$\begin{array}{l}\text { High speed } \\
\text { mission }\end{array}$} & Lift-to-drag ratio & $L / D$ & 17.66 & 18.10 & 18.49 \\
\hline & Center of pressure & $2 y_{C o P} / b$ & 0.412 & 0.379 & 0.383 \\
\hline & Fuel consumption & $m_{F} /\left(R m_{P}\right)$ & $1.634 \times 10^{-4} \mathrm{~km}^{-1}$ & $1.606 \times 10^{-4} \mathrm{~km}^{-1}$ & $1.549 \times 10^{-4} \mathrm{~km}^{-1}$ \\
\hline \multirow{5}{*}{$\begin{array}{l}\text { Design } \\
\text { mission }\end{array}$} & Payload & $m_{P}$ & $35544 \mathrm{~kg}$ & $35463 \mathrm{~kg}$ & $38304 \mathrm{~kg}$ \\
\hline & Used fuel tank volume ratio & $V_{F, \text { req }} / V_{F}$ & 0.998 & 0.920 & 0.969 \\
\hline & Lift-to-drag ratio & $L / D$ & 19.00 & 19.39 & 19.56 \\
\hline & Center of pressure & $2 y_{C o P} / b$ & 0.409 & 0.377 & 0.379 \\
\hline & Fuel consumption & $m_{F} /\left(R m_{P}\right)$ & $1.807 \times 10^{-4} \mathrm{~km}^{-1}$ & $1.784 \times 10^{-4} \mathrm{~km}^{-1}$ & $1.640 \times 10^{-4} \mathrm{~km}^{-1}$ \\
\hline Objective & Combined fuel consumption & $m_{F} /\left(R m_{P}\right)$ & $1.635 \times 10^{-4} \mathrm{~km}^{-1}$ & $1.602 \times 10^{-4} \mathrm{~km}^{-1}$ & $1.533 \times 10^{-4} \mathrm{~km}^{-1}$ \\
\hline
\end{tabular}

Table 10: Results overview of wing optimizations with more flexible wing structure. 
Baseline with more flexible wing
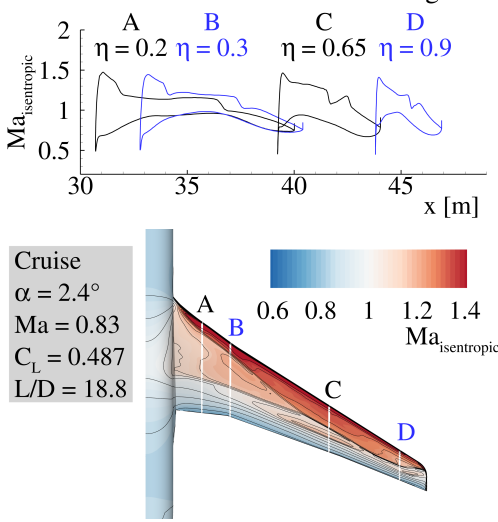

Optimized more flexible wing
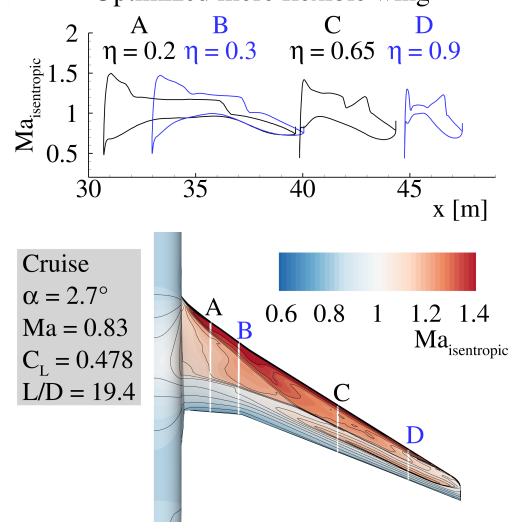

Optimized more flexible wing with MLA
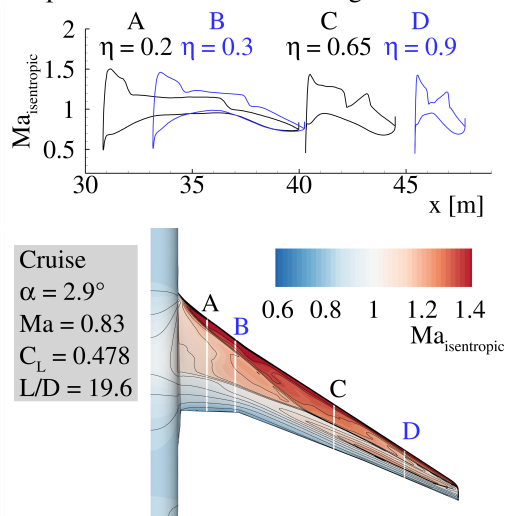

Figure 13: Isentropic Mach number distributions of wing optimizations with more flexible wing structure.

Baseline with more flexible wing

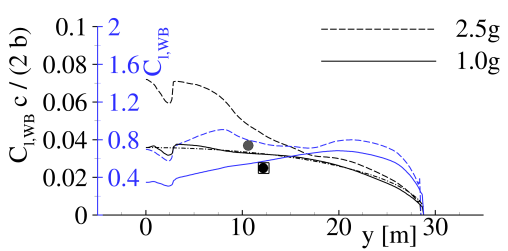

Optimized more flexible wing

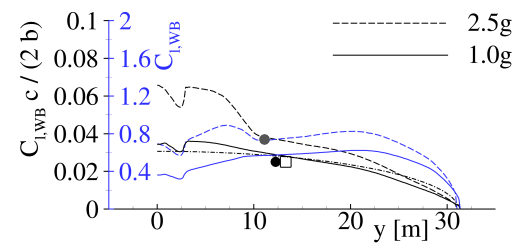

Optimized more flexible wing with MLA

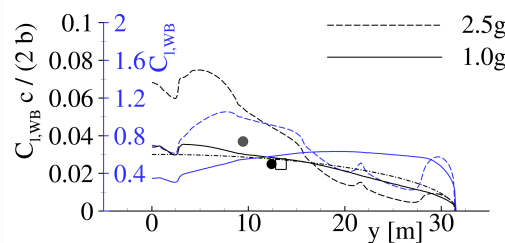

Figure 14: Lift and lift coefficient distributions for cruise and maneuver flight conditions of wing optimizations with more flexible wing structure.

Baseline with more flexible wing

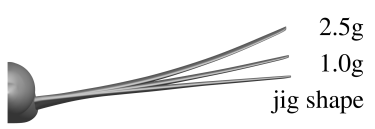

Optimized more flexible wing

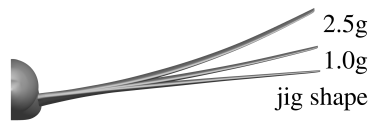

Optimized more flexible wing with MLA

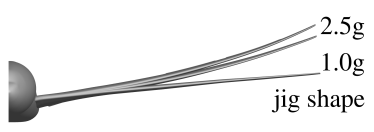

Figure 15: Wing deformations for cruise and maneuver flight conditions of wing optimizations with more flexible wing structure.

Baseline with more flexible wing

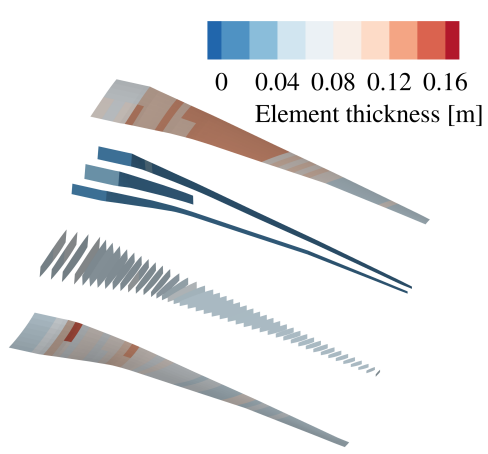

Optimized more flexible wing

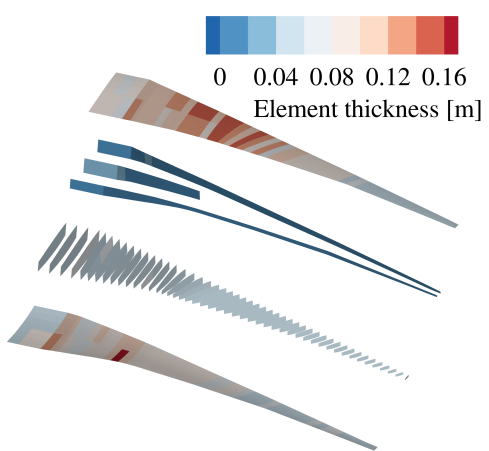

Optimized more flexible wing with MLA

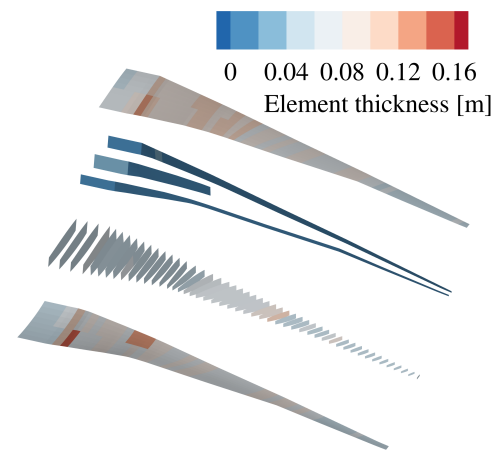

Figure 16: Wing box element thickness (skin thickness + stringer height) distributions of wing optimizations with more flexible wing structure. 


\subsection{Result overview and assessment of the more flexible wing concept}

In Fig. 17 an overview for the results of the aero-structural wing optimizations is shown. For all aero-structural wing analysis the cruise flight performance, the wing mass ratio, and the corresponding combined fuel consumption are summarized.

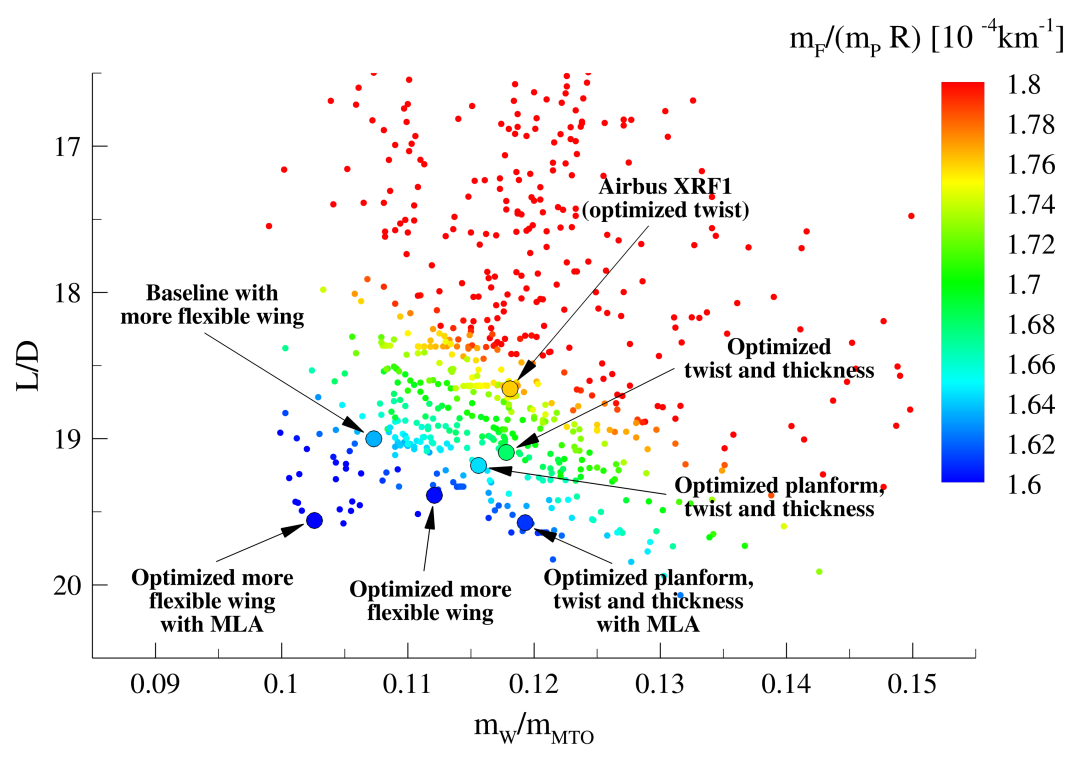

Figure 17: Aero-structural wing optimization results overview.

The combined fuel consumption depends on cruise flight performance and wing mass. The global search in the design space shows different combinations of these two counterparts with the same objective function value. However, the global search has been converged with an acceptable accuracy for practical wing optimizations.

The main results of the aero-structural wing optimizations are summarized in Tab. 11. The percentage of reduction in combined fuel consumption is presented in the last row and shows the potential of more flexible wings to reduce the $\mathrm{CO}_{2}$ emissions per passenger kilometer.

\begin{tabular}{llr}
\hline Optimization & Reference & $\begin{array}{c}\text { Reduction of } \\
\text { combined fuel consumption }\end{array}$ \\
\hline Baseline with more flexible wing & Optimized twist and airfoil thickness (Baseline) & $2.7 \%$ \\
Optimized more flexible wing & Optimized planform, twist, and airfoil thickness & $2.5 \%$ \\
Optimized more flexible wing with MLA & Optimized planform, twist, and airfoil thickness with MLA & $4.8 \%$ \\
\hline Optimized more flexible wing with MLA & Airbus XRF1 (optimized twist, results not shown) & $12.9 \%$ \\
\hline
\end{tabular}

Table 11: More flexible wing optimization results overview.

With the introduced more flexible wing concept a reduction of the combined fuel consumption in the order of $3 \%$ has been achieved for the optimizations without the consideration of active maneuver load alleviation. For wing optimizations with active maneuver load alleviation the more flexible wing concept shows an additional reduction of the combined fuel consumption in the order of $2 \%$ due to snowball effects. In comparison to the twist optimized reference aircraft Airbus XRF1, the introduction of the more flexible wing with active maneuver load alleviation technology, leads to reductions of the combined fuel consumption in the order of $13 \%$ after aero-structural wing optimization. The results for the reference aircraft Airbus XRF1 are not presented here, because of restricted publication rules.

\subsection{Computing time}

The aero-structural wing analysis based on high-fidelity methods requires a relatively high computing effort. For the parallel execution of the flow simulations including the volume mesh deformations the HPC-cluster $\mathrm{C}^{2} \mathrm{~A}^{2} \mathrm{~S}^{2} \mathrm{E}(\mathrm{Center}$ for Computer Applications in AeroSpace Science and Engineering) of the DLR Institute of Aerodynamics and Flow Technology has been used. In this work the flow simulations use 12 nodes of the $\mathrm{C}^{2} \mathrm{~A}^{2} \mathrm{~S}^{2} \mathrm{E}$-cluster, which equates to 288 processor cores. The optimizer and the central process chain Python program including the Python routine for the 


\begin{tabular}{|c|c|c|c|c|}
\hline Process & Simulation program & $\begin{array}{l}\text { Program } \\
\text { calls }\end{array}$ & $\begin{array}{l}\text { Computing } \\
\text { time }\end{array}$ & $\begin{array}{c}\text { Computing } \\
\text { time ratio }\end{array}$ \\
\hline Recalculation of wing geometry (CPACS) & Python program & 1 & $1.4 \mathrm{~min}$ & $1.3 \%$ \\
\hline CAD model update & CATIA ${ }^{\circledR}$ V5 & 1 & $2.7 \mathrm{~min}$ & $2.3 \%$ \\
\hline Aerodynamic surface mesh generation & Pointwise ${ }^{\circledR}$ & 1 & $0.7 \mathrm{~min}$ & $0.6 \%$ \\
\hline Structural model generation & DELiS & 1 & $2.9 \mathrm{~min}$ & $2.5 \%$ \\
\hline Flow simulation and volume mesh deformation & FlowSimulator including TAU-Code & 6 & $72.9 \mathrm{~min}$ & $63.6 \%$ \\
\hline Structural analysis and sizing process & MSC Nastran $^{\mathrm{TM}}$ and HyperSizer ${ }^{\circledR}$ & 5 & $29.8 \mathrm{~min}$ & $26.0 \%$ \\
\hline \multirow[t]{2}{*}{ Data transfer } & - & - & $4.3 \mathrm{~min}$ & $3.7 \%$ \\
\hline & & & $114.6 \mathrm{~min}$ & $100 \%$ \\
\hline
\end{tabular}

Table 12: Example of the required computing time of the disciplinary simulation programs for an aero-structural wing analysis.

recalculation of the wing geometry are running on the HPC-cluster as well. All of the other simulation programs are executed on local workstations.

An example of the required computing time and the corresponding computing time ratio of the disciplinary simulation programs for an aero-structural wing analysis is given in Table 12. In this example 5 fluid-structure coupling iterations have been performed to reach the aeroelastic equilibrium of all considered flight conditions. With approximately $65 \%$, the parallel execution of the flow simulations including the volume mesh deformations for fluid-structure coupling requires the largest percentage of the computing time. Nevertheless, the computing time for the flow simulation is relatively short for aero-structural coupled simulations based on the Reynolds-averaged Navier-Stokes equations (RANS) due to the high degree of parallelization. The structural analysis and sizing process using the finite element method (FEM) is less computationally intensive than the flow simulation. It only needs a percentage of computing time in the order of $25 \%$.

In this context it should be mentioned that the Python routine for recalculating the wing geometry includes the evaluation of the geometrical constraints. If all geometrical constraints are fulfilled for the given set of design parameters, the process chain will continue with the CAD model update, otherwise the process chain will terminate. With this approach the computing time is reduced significantly, because the time consuming aero-structural wing analysis is only performed for geometrically feasible wing designs.

To reduce the computing time on the HPC-cluster a design space exploration has been executed on a local workstation in order to find feasible wing planform designs in front of the wing planform optimizations. This has been done by the usage of the Python program for recalculating the wing geometry, which includes the evaluation of the geometrical constraints. The design parameter sets of all feasible wing planform designs have been used as the samples in the initial DoE of the surrogate based optimization strategy. The corresponding results of the aero-structural wing analysis are included in Fig. 17.

It can be stated that a global aero-structural wing optimization with 17 design parameters requires an overall computing time in the order of two weeks. Due to the reusability of many results for constructing the surrogate models of different wing optimizations, the overall sum of aero-structural wing analysis in this work is in the order of 750 .

\section{Conclusion and Outlook}

In this work, the assessment of the more flexible wing concept has been successfully demonstrated by using an integrated process for aero-structural wing optimization based on high fidelity simulation methods. The comparison of optimization results with the same objective function, design parameters, and constraints allows a proper technology assessment. In order to find the optimum trade-off between aerodynamic performance and wing mass for the more flexible wing, the twist and airfoil thickness distribution and the wing planform design parameters have been involved in the wing optimization. The results of this optimization show the expected reduction of the combined fuel consumption due to an increased aerodynamic performance under cruise flight conditions. This increase in aerodynamic performance has been achieved with higher aspect ratio and reduced taper ratio of the wing.

With the application of more flexible wings, the significance of static aeroelastic effects for the prediction of cruise flight performance and passive maneuver load alleviation has been shown. The structural wing sizing of the modified structural concept, with increased strain allowable, results in a significant wing mass reduction and more wing flexibility. This mass reduction of the more flexible wing can be explained with the increased utilization of the composite material and the passive load alleviation under maneuver flight conditions.

Within the wing planform optimizations only $1 \%$ of the wing geometries in the selected design space have fulfilled the geometrical constraints and have been considered in the aero-structural wing analysis. This observation shows the importance of the consideration of landing gear integration and control surface constraints.

Another aspect of the wing optimization results obtained, is the resulting thin inboard wing, which contradicts 
conceptual design estimations based on handbook methods and is significantly lower than the values of current aircraft designs. Hence, the optimized wing geometries with thin inboard wing region require further investigation and validation. Furthermore, the used fuel tank volume ratios for the design mission are on the upper limit due to the thin inboard wings. One reason for a thicker inboard wing is the requested flexibility of airlines for extended range missions, which requires additional fuel tank volume.

In the future, the processes for wing optimization have to be extended with engine design and integration, gust loads prediction, and take-off and landing constraints. Furthermore, the airfoil design has to be integrated with the usage of an airfoil catalog or by gradient based shape optimization. With increasing computational resources and progress in numerical processes, based in high fidelity methods, it is possible for more disciplines and their interactions to be considered in the assessment of new aircraft technologies and configurations.

\section{Acknowledgments}

The authors would like to thank Airbus for providing the XRF1 research test case as an opportunity for demonstrating the approaches presented in this publication.

\section{References}

[1] European Commision. Flightpath 2050 Europe's Vision for Aviation. Luxembourg, Belgium: Office for Official Publications of the European Communities, 2011. uRL: https://ec. europa.eu/transport/sites/transport/files/modes/air/doc/flightpath2050.pdf.

[2] F. Collier et al. "Environmentally Responsible Aviation-Real Solutions for Environmental Challenges Facing Aviation". In: 27th Interantional Congress of the Aeronautical Sciences, ICAS 2010, Nice, France. ICAS Conference Paper NF1676L-11223. Sept. 2010. URL: https: //ntrs.nasa.gov/citations/20100033776.

[3] G. M. Bezos-O'Connor et al. "Fuel Efficiencies Through Airframe Improvements". In: 3rd AIAA Atmospheric Space Environments Conference. AIAA 2011-3530. June 2011. eprint: https : / / arc . aiaa . org/doi / pdf / 10 . 2514/6.2011-3530. URL: https : //doi.org/10.2514/6.2011-3530.

[4] G. W. K. Kenway and J. R. R. A. Martins. "High-fidelity aerostructural optimization considering buffet onset". In: 16th AIAA/ISSMO Multidisciplinary Analysis and Optimization Conference, Texas, USA. June 2015. eprint: https://arc . aiaa.org/doi/pdf/10.2514/6. 2015-2790. URL: https://doi .org/10.2514/6.2015-2790.

[5] R. J. White. "Improving the Airplane Efficiency by Use of Wing Maneuver Load Alleviation". In: Journal of Aircraft 8.10 (1971), pp. 769-775. eprint: https://arc.aiaa.org/doi/pdf/10.2514/3.59169. uRL: https://doi.org/10.2514/3.59169.

[6] G. E. Bendixen et al. "Digital active control system for load alleviation for the Lockheed L-1011". In: The Aeronautical Journal 85.849 (1981), pp. 430-436.

[7] A. S.A.S. A350 high-lift devices combine simplicity with fuel savings. 2007. uRL: https://www . airbus. com/newsroom/news/en/2007/ 08/a350-high-lift-devices-combine-simplicity-with-fuel-savings.html (visited on Oct. 6, 2020).

[8] J. Xu and I. Kroo. “Aircraft Design with Active Load Alleviation and Natural Laminar Flow”. In: Journal of Aircraft 51.5 (2014), pp. 1532-1545. eprint: https://doi.org/10.2514/1.CQ32402. uRL: https://doi .org/10.2514/1.CQ32402.

[9] A. Sgueglia et al. "Multidisciplinary Design Optimization Framework with Coupled Derivative Computation for Hybrid Aircraft". In: Journal of Aircraft 57.4 (2020), pp. 715-729. eprint: https : / / arc . aiaa . org / doi / pdf / 10 . 2514/1 . C035509. uRL: https : //doi.org/10.2514/1.CQ35509.

[10] A. Papageorgiou et al. "Multidisciplinary and Multifidelity Framework for Evaluating System-of-Systems Capabilities of Unmanned Aircraft". In: Journal of Aircraft 57.2 (2020), pp. 317-332. eprint: https : //arc . aiaa . org/doi /pdf/10.2514/1 . CQ35640. uRL: https://doi.org/10.2514/1.CQ35640.

[11] R. Priem et al. "An efficient application of Bayesian optimization to an industrial MDO framework for aircraft design". In: AIAA Aviation Forum 2020. June 2020. eprint: https: //arc . aiaa.org/doi/pdf/10.2514/6.2020-3152. uRL: https://doi . org/10.2514/6.2020-3152.

[12] D. Sarojini et al. "A Certification-Driven Platform for Multidisciplinary Design Space Exploration in Airframe Early Preliminary Design". In: AIAA Aviation Forum 2020. June 2020. eprint: https : / / arc . aiaa . org / doi / pdf / 10 . 2514/6 . 2020-3157. URL: https: //doi.org/10.2514/6.2020-3157.

[13] B. Boden et al. "Distributed Multidisciplinary Optimization and Collaborative Process Development using RCE". In: AIAA Aviation 2019 Forum. June 2019. eprint: https://arc . aiaa.org/doi/pdf/10.2514/6.2019-2989. uRL: https://doi .org/10.2514/6.2019-2989.

[14] C. Ilic et al. "Cybermatrix Protocol: A Novel Approach to Highly Collaborative and Computationally Intensive Multidisciplinary Aircraft Optimization". In: AIAA Aviation Forum 2020. June 2020. eprint: https : //arc . aiaa . org/doi /pdf/10.2514/6. 2020-3169. uRL: https://doi.org/10.2514/6.2020-3169.

[15] J. T. Hwang et al. "High-Fidelity Design-Allocation Optimization of a Commercial Aircraft Maximizing Airline Profit". In: Journal of Aircraft 56.3 (2019), pp. 1164-1178. eprint: https://arc.aiaa.org/doi/pdf/10.2514/1.C035082. URL: https://doi .org/10.2514/1. CQ35082.

[16] S. Roy et al. "Monolithic Approach for Next-Generation Aircraft Design Considering Airline Operations and Economics". In: Journal of Aircraft 56.4 (2019), pp. 1565-1576. eprint: https: //arc . aiaa.org/doi/pdf/10.2514/1. CQ35312. uRL: https://doi .org/10. $2514 / 1 . \operatorname{CQ353} 12$.

[17] A. Jameson et al. "Multi-point Aero-Structural Optimization of Wings Including Planform Variations". In: 45th Aerospace Sciences Meeting and Exhibit, Reno, Nevada, USA. AIAA 2007-764. 2007. eprint: https : //arc . aiaa.org/doi/pdf/10.2514/6.2007-764. uRL: https://doi.org/10.2514/6.2007-764. 
[18] J. R. R. A. Martins and J. T. Hwang. "Review and Unification of Methods for Computing Derivatives of Multidisciplinary Computational Models". In: AIAA Journal 51.11 (2013), pp. 2582-2599. eprint: https : / / arc . aiaa . org/doi / pdf/10 . 2514/1 . J052184. URL: https://doi.org/10.2514/1.J052184

[19] R. P. Liem et al. "Multimission Aircraft Fuel-Burn Minimization via Multipoint Aerostructural Optimization". In: AIAA Journal 53.1 (2015), pp. 104-122. eprint: https://arc.aiaa.org/doi/pdf/10.2514/1. J052940. uRL: https://doi .org/10.2514/1. J052940.

[20] S. Keye et al. "Aero-Structural Optimization of the NASA Common Research Model”. In: 18th AIAA/ISSMO Multidisciplinary Analysis and Optimization Conference. AIAA 2017-4145. June 2017. eprint: https://arc .aiaa.org/doi/pdf/10.2514/6.2017-4145. uRL: https://doi.org/10.2514/6.2017-4145.

[21] C. A. Mader et al. "Aerostructural Optimization of the D8 Wing with Varying Cruise Mach Numbers". In: 18th AIAA/ISSMO Multidisciplinary Analysis and Optimization Conference, Denver, USA. June 2017. eprint: https://arc. aiaa.org/doi/pdf/10.2514/6.2017-4436. URL: https://doi.org/10.2514/6.2017-4436.

[22] T. R. Brooks et al. “Aerostructural Tradeoffs for Tow-Steered Composite Wings”. In: Journal of Aircraft 57.5 (2020), pp. 787-799. eprint: https://arc.aiaa.org/doi/pdf/10.2514/1.CQ35699. uRL: https://doi .org/10.2514/1.CQ35699.

[23] M. Abu-Zurayk et al. "Sensitivity-based Multifidelity Multidisciplinary Optimization of a Powered Aircraft Subject to a Comprehensive Set of Loads". In: AIAA Aviation Forum 2020. June 2020. eprint: https : / /arc . aiaa . org/doi/pdf/10.2514/6. 2020-3168. uRL: https://doi.org/10.2514/6.2020-3168.

[24] S. Görtz et al. "Multi-Level MDO of a Long-Range Transport Aircraft Using a Distributed Analysis Framework". In: 18th AIAA/ISSMO Multidisciplinary Analysis and Optimization Conference, Denver, USA. June 2017. eprint: https://arc .aiaa.org/doi/pdf/10.2514/6 2017-4326. URL: https://doi.org/10.2514/6.2017-4326.

[25] S. Görtz et al. "DLR-Projekt VicToria - Virtual Aircraft Technology Integration Platform". In: Deutscher Luft- und Raumfahrtkongress 2018. Sept. 2018. uRL: https://elib.dlr.de/121695.

[26] S. Görtz et al. "Overview of Collaborative Multi-Fidelity Multidisciplinary Design Optimization Activities in the DLR Project VicToria". In: AIAA Aviation Forum 2020. June 2020. eprint: https : //arc . aiaa . org/doi / pdf / 10.2514/6.2020-3167. URL: https: //doi.org/10.2514/6.2020-3167.

[27] T. F. Wunderlich et al. "Overview of collaborative high performance computing-based MDO of transport aircraft in the DLR project VicToria". In: Deutscher Luft- und Raumfahrtkongress 2018. Sept. 2018. uRL: https://elib.dlr. de/125555.

[28] T. F. Wunderlich et al. "Multidisciplinary optimization of an NLF forward swept wing in combination with aeroelastic tailoring using CFRP". In: CEAS Aeronautical Journal 8.4 (2017), pp. 673-690. uRL: https: //doi .org/10.1007/s13272-017-0266-z.

[29] T. F. Wunderlich and L. Reimer. "Integrated Process Chain for Aerostructural Wing Optimization and Application to an NLF Forward Swept Composite Wing". In: AeroStruct: Enable and Learn How to Integrate Flexibility in Design. Ed. by R. Heinrich. Vol. 138. Notes on Numerical Fluid Mechanics and Multidisciplinary Design (NNFM). Cham: Springer International Publishing, 2018, pp. 3-33. uRL: https: //doi.org/10.1007/978-3-319-72020-3_1.

[30] J. R. R. A. Martins and A. B. Lambe. "Multidisciplinary Design Optimization: A Survey of Architectures". In: AIAA Journal 51.9 (2013), pp. 2049-2075. eprint: https://arc.aiaa.org/doi/pdf/10.2514/1.J051895. uRL: https://doi .org/10.2514/1.J051895.

[31] T. F. Wunderlich et al. "Global Aero-Structural Design Optimization of More Flexible Wings for Commercial Aircraft". In: AIAA Aviation Forum 2020. June 2020. eprint: https://arc . aiaa.org/doi/pdf/10.2514/6.2020-3170. uRL: https://doi .org/10.2514/6.2020-3170.

[32] A. B. Lambe and J. R. R. A. Martins. "Extensions to the Design Structure Matrix for the Description of Multidisciplinary Design Analysis and Optimization Processes”. In: Structural and Multidisciplinary Optimization 46 (2012), pp. 273-284. uRL: https: //doi . org/10.1007/ s00158-012-0763-y

[33] C. M. Liersch and M. Hepperle. "A distributed toolbox for multidisciplinary preliminary aircraft design". In: CEAS Aeronautical Journal 2.1-4 (2011), pp. 57-68. uRL: https://doi .org/10.1007/s13272-011-0024-6.

[34] B. Nagel et al. "Communication in Aircraft Design Can we Establish a Common Language". In: 28th Interantional Congress of the Aeronautical Sciences, ICAS 2012. ICAS Conference Paper. Sept. 2012. uRL: https: //elib.dlr. de/134586.

[35] A. Rempke. "Netzdeformation mit Elastizitätsanalogie in multidisziplinärer FlowSimulator-Umgebung". In: 20. DGLR - Fach - Symposium der STAB 2016. Vol. 2016. 2016, pp. 128-129. uRL: https: //elib.dlr.de/109263.

[36] M. Meinel and G. O. Einarsson. "The FlowSimulator framework for massively parallel CFD applications". In: PARA 2010 conference, 6-9 June, Reykjavik, Iceland. 2010. uRL: https://elib.dlr.de/67768.

[37] L. Reimer et al. "Multidisciplinary Analysis Workflow with the FlowSimulator". In: Proceedings of the Onera Scientific Day 2012-CFD Workflow: Mesh, Solving, Visualizing, ... Ed. by C. Benoit et al. Vol. 19. Amphithéâtre Becquerel, École Polytechnique, Palaiseau, 2012, pp. 23-30. URL: https://elib.dlr.de/78601.

[38] L. Reimer et al. "Towards Higher-Precision Maneuver and Gust Loads Computations of Aircraft: Status of Related Features in the CFD-Based Multidisciplinary Simulation Environment FlowSimulator”. In: New Results in Numerical and Experimental Fluid Mechanics XII. Ed. by A. Dillmann et al. Cham: Springer International Publishing, 2020, pp. 597-607. uRL: https://doi .org/10.1007/978-3-030-25253-3_57.

[39] T. Führer et al. “Automated model generation and sizing of aircraft structures”. In: Aircraft Engineering and Aerospace Technology 88.2 (2016), pp. 268-276. uRL: https://elib.dlr.de/103351.

[40] C. Geuzaine and J.-F. Remacle. "Gmsh: A 3-D finite element mesh generator with built-in pre- and post-processing facilities". In: International Journal for Numerical Methods in Engineering 79.11 (2009), pp. 1309-1331. eprint: https://onlinelibrary.wiley.com/doi/pdf/10. 1002/nme. 2579. uRL: https://onlinelibrary.wiley.com/doi/abs/10.1002/nme. 2579.

[41] R. Kamakoti and W. Shyy. "Fluid-structure interaction for aeroelastic applications". In: Progress in Aerospace Sciences 40.8 (2005), pp. 535-558. URL: http://www.sciencedirect.com/science/article/pii/S0376042105000084.

[42] X. B. Lam et al. "Coupled Aerostructural Design Optimization Using the Kriging Model and Integrated Multiobjective Optimization Algorithm". In: Journal of Optimization Theory and Applications 142.3 (2009), pp. 533-556. URL: https://doi . org/10.1007/s10957-009-9520-9.

[43] T. Gerhold. "Overview of the Hybrid RANS TAU-Code". In: MEGAFLOW - Numerical Flow Simulation for Aircraft Design. Ed. by N. Kroll and J. K. Fassbender. Vol. 89. Berlin, Heidelberg: Springer Berlin Heidelberg, 2005, pp. 81-92. URL: https://doi . org/10. 1007/3-54032382-1_5. 
[44] D. Schwamborn et al. "The DLR TAU-Code: Recent Applications in Research and Industry". In: European Conference on Computational Fluid Dynamics, ECCOMAS CFD 2006 Conference, Delft, The Netherlands. 2006. uRL: https://elib.dlr.de/22421.

[45] E. N. Tinoco et al. "Summary Data from the Sixth AIAA CFD Drag Prediction Workshop: CRM Cases". In: Journal of Aircraft 55.4 (2018), pp. 1352-1379. eprint: https://arc.aiaa.org/doi/pdf/10.2514/1.CQ34409. urL: https://doi .org/10.2514/1.C034409.

[46] S. Dähne et al. "Steps to Feasibility for Laminar Wing Design in a Multidisciplinary Environment". In: 29th Congress of the International Council of the Aeronautical Sciences, ICAS 2014. Sept. 2014. urL: https: //elib.dlr. de/90644.

[47] H. Barnewitz and B. Stickan. "Improved Mesh Deformation". In: Management and Minimisation of Uncertainties and Errors in Numerical Aerodynamics: Results of the German collaborative project MUNA. Ed. by B. Eisfeld et al. Vol. 122. Berlin, Heidelberg, 2013, pp. 219-243. URL: https: //doi .org/10.1007/978-3-642-36185-2_9.

[48] G. A. Wilke. "Variable-Fidelity Methodology for the Aerodynamic Optimization of Helicopter Rotors". In: AIAA Journal 57.8 (2019), pp. 3145-3158. eprint: https://arc.aiaa.org/doi/pdf/10.2514/1.J056486. uRL: https://doi .org/10.2514/1.J056486.

[49] D. R. Jones et al. "Efficient Global Optimization of Expensive Black-Box Functions”. In: Journal of Global Optimization 13.4 (1998), pp. 455-492. URL: https: //doi .org/10.1023/A: 1008306431147.

[50] A. Forrester et al. Engineering Design via Surrogate Modelling: A Practical Guide. Wiley, 2008. urL: https: //doi . org/10.1002/ 9780470770801.

[51] D. G. Krige. "A Statistical Approach to Some Basic Mine Valuation Problems on the Witwatersrand”. In: Journal of the Chemical, Metallurgical and Mining Society of South Africa 52.6 (Dec. 1951), pp. 119-139. uRL: http://doi . org/10.2307/3006914.

[52] Y. Xiong et al. "A New Variable-Fidelity Optimization Framework Based on Model Fusion and Objective-Oriented Sequential Sampling". In Journal of Mechanical Design 130.11 (2008), p. 111401. URL: https://doi .org/10.1115/1.2976449.

[53] J. Roskam. Airplane Design Part 1: Preliminary Sizing of Airplanes. Lawrence, Kansas, USA: Design, Analysis and Research Corporation, 120 East Ninth Street, Suite 2, Lawrence, Kansas, 66044, USA, 1989.

[54] D. P. Raymer. Aircraft Design: A Conceptual Approach. Sixth Edition. AIAA education series. American Institute of Aeronautics and Astronautics, 2019. uRL: https://doi .org/10.2514/4.105746.

[55] L. R. Jenkinson et al. Civil Jet Aircraft Design. AIAA education series. American Institute of Aeronautics and Astronautics (AIAA), 1999. URL: https://doi.org/10.2514/4.473500.

[56] J. D. Mattingly et al. Aircraft Engine Design. Second Edition. American Institute of Aeronautics and Astronautics, 2002. urL: https : //doi.org/10.2514/4.861444.

[57] L. M. Nicolai and G. Carichner. Fundamentals of Aircraft and Airship Design. Vol. 1. AIAA education series. American Institute of Aeronautics and Astronautics, 2010. URL: https://doi .org/10.2514/4.867538.

[58] N. S. Currey. Aircraft Landing Gear Design: Principles and Practices. AIAA Education Series. American Institute of Aeronautics and Astronautics, 1988. uRL: https://doi .org/10.2514/4.861468.

[59] M. H. Sadraey. Aircraft Design: A Systems Engineering Approach. Chichester, United Kingdom: John Wiley and Sons, Ltd, 2013.

[60] A350 aircraft characteristics, airport and maintenance planning. AIRBUS S.A.S. Blagnac Cedex, France, May 2020. uRL: https : //www.airbus.com/content/dam/corporate-topics/publications/backgrounders/techdata/aircraft_characteristics/ Airbus-Commercial-Aircraft-AC-A350-900-1000.pdf.

[61] M.-H.-1.-3. Military. Composite Materials Handbook, Polymer Matrix Composites: Materials Usage, Design, and Analysis. Vol. 3 of 5. US Department of Defense, June 2002.

[62] T. Bach and C. Hühne. "Structural Optimization of Stiffened Composite Panels for Highly Flexible Aircraft Wings". In: 12th World Congress of Structural and Multidisciplinary Optimization (WCSMO), Braunschweig, Germany. Ed. by A. Schumacher et al. Cham: Springer International Publishing, Jan. 2018, pp. 838-849. urL: https://doi.org/10.1007/978-3-319-67988-4_64.

[63] T. F. Wunderlich. "Multidisziplinäre Optimierung von Flügeln für Verkehrsflugzeuge mit Berücksichtigung der statischen Aeroelastizität". PhD thesis. Technische Universität Braunschweig, Mar. 2013. uRL: https://elib.dlr.de/88002.

[64] T. F. Wunderlich. "Multidisciplinary wing optimization of commercial aircraft with consideration of static aeroelasticity". In: $C E A S$ Aeronautical Journal 6.3 (2015), pp. 407-427. uRL: https: //doi .org/10.1007/s13272-015-0151-6. 